OPEN ACCESS

Edited by:

Hua-Bin Li,

Sun Yat-sen University, China

Reviewed by:

Zaixiang Lou,

Jiangnan University, China

Euna Oh,

University of Alberta, Canada Derrick Richard Samuelson, Louisiana State University,

United States

*Correspondence:

Annie M. Donoghue

annie.donoghue@usda.gov

Specialty section:

This article was submitted to

Food Microbiology,

a section of the journa

Frontiers in Microbiology

Received: 20 February 2019

Accepted: 25 July 2019

Published: 07 August 2019

Citation:

Wagle BR, Upadhyay $A$, Upadhyaya I, Shrestha S, Arsi K, Liyanage $R$, Venkitanarayanan $K$,

Donoghue DJ and Donoghue AM (2019) Trans-Cinnamaldehyde,

Eugenol and Carvacrol Reduce

Campylobacter jejuni Biofilms and Modulate Expression of Select

Genes and Proteins.

Front. Microbiol. 10:1837. doi: 10.3389/fmicb.2019.01837

\section{Trans-Cinnamaldehyde, Eugenol and Carvacrol Reduce Campylobacter jejuni Biofilms and Modulate Expression of Select Genes and Proteins}

\author{
Basanta R. Wagle', Abhinav Upadhyay', Indu Upadhyaya ${ }^{3}$, Sandip Shrestha', \\ Komala Arsi ${ }^{1}$, Rohana Liyanage ${ }^{4}$, Kumar Venkitanarayanan ${ }^{2}$, Dan J. Donoghue ${ }^{1}$ and \\ Annie M. Donoghue ${ }^{5 *}$
}

\begin{abstract}
'Department of Poultry Science, University of Arkansas, Fayetteville, AR, United States, ${ }^{2}$ Department of Animal Science, University of Connecticut, Storrs, CT, United States, ${ }^{3}$ School of Agriculture, Tennessee Tech University, Cookeville, TN, United States, ${ }^{4}$ Department of Chemistry and Biochemistry, University of Arkansas, Fayetteville, AR, United States, ${ }^{5}$ Poultry Production and Product Safety Research Unit, United States Department of Agriculture - Agriculture Research Station, Fayetteville, AR, United States
\end{abstract}

Campylobacter jejuni is the leading cause of human foodborne illness globally, and is strongly linked with the consumption of contaminated poultry products. Several studies have shown that $C$. jejuni can form sanitizer tolerant biofilm leading to product contamination, however, limited research has been conducted to develop effective control strategies against $C$. jejuni biofilms. This study investigated the efficacy of three generally recognized as safe status phytochemicals namely, trans-cinnamaldehyde (TC), eugenol (EG), or carvacrol (CR) in inhibiting C. jejuni biofilm formation and inactivating mature biofilm on common food contact surfaces at 20 and $37^{\circ} \mathrm{C}$. In addition, the effect of phytochemicals on biofilm architecture and expression of genes and proteins essential for biofilm formation was evaluated. For the inhibition study, C. jejuni was allowed to form biofilms either in the presence or absence of sub-inhibitory concentrations of TC (0.75 mM), EG $(0.61 \mathrm{mM})$, or $\mathrm{CR}(0.13 \mathrm{mM})$ for $48 \mathrm{~h}$ and the biofilm formation was quantified at 24-h interval. For the inactivation study, C. jejuni biofilms developed at 20 or $37^{\circ} \mathrm{C}$ for $48 \mathrm{~h}$ were exposed to the phytochemicals for 1 , 5, or $10 \mathrm{~min}$ and surviving C. jejuni in the biofilm were enumerated. All phytochemicals reduced C. jejuni biofilm formation as well as inactivated mature biofilm on polystyrene and steel surface at both temperatures $(P<0.05)$. The highest dose of TC $(75.64 \mathrm{mM})$, EG $(60.9 \mathrm{mM})$ and $\mathrm{CR}$ (66.56 $\mathrm{mM}$ ) inactivated (> 7 log reduction) biofilm developed on steel $\left(20^{\circ} \mathrm{C}\right)$ within $5 \mathrm{~min}$. The genes encoding for motility systems ( $f(a A, f l a B$, and $f(g A)$ were downregulated by all phytochemicals $(P<0.05)$. The expression of stress response (cos $R, a h p C)$ and cell surface modifying genes (waaF) was reduced by EG. LC-MS/MS based proteomic analysis revealed that $\mathrm{TC}, \mathrm{EG}$, and $\mathrm{CR}$ significantly downregulated the expression of NapA protein required for oxidative stress response. The expression of chaperone protein DnaK and bacterioferritin required for biofilm formation was reduced by TC 
and CR. Scanning electron microscopy revealed disruption of biofilm architecture and loss of extracellular polymeric substances after treatment. Results suggest that TC, $E G$, and $C R$ could be used as a natural disinfectant for controlling C. jejuni biofilms in processing areas.

Keywords: C. jejuni, biofilm, phytochemicals, inhibition, inactivation, gene/protein expression

\section{INTRODUCTION}

Campylobacter is one of the major foodborne pathogens that causes gastroenteritis in humans worldwide (Marder et al., 2017). Recent reports have shown that the incidence of Campylobacter infections has increased by $10 \%$ in 2017 compared to 20142016 with an annual incidence of 17.83 per 100,000 people in the United States (Marder et al., 2017). Among the major Campylobacter species, Campylobacter jejuni is responsible for approximately $90 \%$ of the reported campylobacteriosis cases in humans (Cody et al., 2013). In addition, C. jejuni infections have been associated with the occurrence of Guillain-Barré syndrome and reactive arthritis causing significant economic losses and disease burden globally (Spiller, 2007; Gradel et al., 2009; Hoffmann et al., 2012).

The primary source of human $C$. jejuni infections is the handling and/or consumption of contaminated poultry products (Rosner et al., 2017). The survival of C. jejuni in the environment such as water and feed plays a critical role in C. jejuni colonization in the birds and subsequent contamination of poultry products during carcass processing (Annan-Prah and Janc, 1988; Dhillon et al., 2006; Boysen et al., 2016). Several studies have shown that the biofilm-forming capacity in bacteria facilitates increased tolerance to sanitizers (Somers et al., 1994; Trachoo and Frank, 2002; Trachoo et al., 2002; Melo et al., 2017). Therefore, there is a high possibility that product contamination in processing environment could be due to the presence of biofilms. A biofilm is an assemblage of surfaceassociated microbial communities embedded within the matrix of extracellular polymeric substances (Donlan, 2002; Donlan and Costerton, 2002). The ability of C. jejuni to form biofilm has been demonstrated on different surfaces, including plastic, glass and steel under different oxygen concentrations (Trachoo et al., 2002; Reuter et al., 2010; Bronowski et al., 2014; Brown et al., 2014; Bronnec et al., 2016). Moreover, studies have demonstrated that C. jejuni biofilm formation can be enhanced by atmospheric oxygen and in the presence of chicken meat juice (Reuter et al., 2010; Brown et al., 2014). Thus, C. jejuni biofilms constitute a significant food safety hazard.

The formation of bacterial biofilm begins with initial attachment of bacteria to a surface. The surface attachment strengthens, and the bacterial community becomes irreversibly attached to the target surface. This is followed by maturation of the biofilm and dispersion of bacteria to new location (Donlan and Costerton, 2002). A number of genes that contribute to biofilm formation have been characterized in C. jejuni (Bronowski et al., 2014). Several genes coding for motility (Joshua et al., 2006; Kalmokoff et al., 2006; Kim et al., 2015) are essential for biofilm formation. These include
flaA, flaB, flaC, flaG, fliA, flis, flgA, and flhA. In addition, genes encoding stress response (spot, csrA, ahpC, $\cos R$, and cprS) (Fields and Thompson, 2008; McLennan et al., 2008; Svensson et al., 2009; Oh and Jeon, 2014; Turonova et al., 2015), bacterial cell surface modifications (peb4, waaF) (Asakura et al., 2007; Naito et al., 2010) and quorum sensing (luxS) (Reeser et al., 2007) are also critical for biofilm formation and maturation in C. jejuni. One of the critical components of bacterial biofilm is the exopolysaccharide layer (EPS), which protects underlying bacterial population from harsh environmental conditions. The impermeability of EPS along with the slower growth rates and metabolism of bacteria in the biofilms makes them resistant to disinfectants, antimicrobials and antibiotics (Reuter et al., 2010; Borges et al., 2016). In a recent study, C. jejuni population in biofilms was found to exhibit up to 32 -fold higher resistance to gentamicin than in the corresponding planktonic forms (Malik et al., 2017). In addition, biofilm facilitates $C$. jejuni to survive for a longer period of time (up to 24 days) as compared to planktonic cells under aerobic conditions or in water (Joshua et al., 2006; Lehtola et al., 2006). Thus, developing appropriate processing plant hygiene and sanitation are critical for controlling C. jejuni biofilms.

Current intervention approaches for controlling C. jejuni biofilms include use of chemicals (Somers et al., 1994; Trachoo et al., 2002; Melo et al., 2017), biofilm-degrading enzymes (Brown et al., 2015; Kim et al., 2017) and application of bacteriophages (Siringan et al., 2011). Chemical disinfectants such as chlorine, trisodium phosphate and quaternary ammonium compounds have been extensively investigated for their antibiofilm efficacy against C. jejuni, however, these compounds have limited effectiveness in controlling C. jejuni biofilm, especially in the presence of organic matter (Northcutt et al., 2005; Oyarzabal, 2005). Moreover, production of mutagens is of concern (Dore, 2015). The use of biofilm-degrading enzymes for controlling biofilms has been reported in various bacteria, including C. jejuni (Brown et al., 2015; Kim et al., 2017). However, the efficacy of biofilm-degrading enzyme could be reduced with the production of high quantities of EPS and proteolytic activity of exoenzymes produced by the mature biofilms (Whitchurch et al., 2002). Similarly, treatment of C. jejuni biofilms with bacteriophages has limited application due to the chance of emergence of resistance strains (Siringan et al., 2011). Therefore, there is a need for a novel strategy to control C. jejuni biofilms.

Phytochemicals have been used as natural antimicrobials for treating human infections since ancient time. The majority of phytochemicals are secondary metabolites produced as a defense mechanism to protect plants from pathogenic microorganisms 
(Borges et al., 2016). A variety of phytochemicals have been evaluated for their antibacterial effect against foodborne pathogens and several active components have been identified (Burt, 2004; Holley and Patel, 2005). However, very few studies have investigated the potential of phytochemicals for controlling C. jejuni biofilms. Trans-cinnamaldehyde (TC) is an aldehyde extracted from the bark of cinnamon (Cinnamomum zeylandicum), whereas eugenol (EG) and carvacrol (CR) are the active components of clove oil (Eugenia caryophyllus) and oregano oil (Origanum glandulosum), respectively. All the aforementioned phytochemicals are classified as generally recognized as safe by the United States Food and Drug Administration (21 Code of Federal Regulation part 172.515) (Adams et al., 2004, 2005; Knowles et al., 2005). Previous studies have demonstrated the antibiofilm effect of TC, EG and CR in various bacteria such as Salmonella Typhimurium (Trevisan et al., 2018), S. Enteritidis (Čabarkapa et al., 2019), Listeria monocytogenes (Upadhyay et al., 2013) and Pseudomonas aeruginosa (Letsididi et al., 2018; Lou et al., 2019). However, their antibiofilm effect in C. jejuni has not been determined.

In this study, we investigated the antibiofilm efficacy of TC, EG, and CR against C. jejuni at two temperatures (20 and $37^{\circ} \mathrm{C}$ ) and on two surfaces (polystyrene and stainlesssteel) that are commonly encountered in processing plant environment. The effect of phytochemical treatments on C. jejuni biofilm architecture was visualized using scanning electron microscopy and confocal laser scanning microscopy. Moreover, the effects of TC, EG, and CR on the transcription of C. jejuni genes and proteins critical for biofilm formation were determined.

\section{MATERIALS AND METHODS}

\section{C. jejuni Strain and Culture Conditions}

Campylobacter jejuni NCTC 11168 strain was cultured in $10 \mathrm{~mL}$ of Campylobacter enrichment broth (CEB; International Diagnostics Group, Bury, Lancashire, United Kingdom) and incubated under microaerophilic condition $\left(5 \% \mathrm{O}_{2}, 10 \% \mathrm{CO}_{2}\right.$, and $85 \% \mathrm{~N}_{2}$ ) at $42^{\circ} \mathrm{C}$ for $48 \mathrm{~h}$. Following growth, C. jejuni was centrifuged and washed twice with Butterfield's phosphate diluent (BPD, $0.625 \mathrm{mM}$ potassium dihydrogen phosphate, $\mathrm{pH} 7.2$ ) and resuspended in CEB to use as inoculum.

\section{Preparation of Chicken Meat Juice}

A previously published method was used for the preparation of chicken meat juice (Birk et al., 2004). Briefly, frozen whole chickens were obtained from the University of Arkansas poultry pilot processing plant (Fayetteville, AR, United States) and thawed overnight at $4^{\circ} \mathrm{C}$. The meat juice was collected and centrifuged at 4,000 rpm for $20 \mathrm{~min}$ to remove debris followed by filter sterilization $(0.2 \mu \mathrm{m}$ cellulose acetate membrane; VWR International, United States). Based on published literature (Brown et al., 2014) and growth curve analysis, chicken meat juice was added to CEB at 5\% level and used for biofilm experiments.

\section{Determination of $C$. jejuni Biofilm Formation on Polystyrene Plates and Stainless-Steel Coupons}

The biofilm formation of C. jejuni on polystyrene plates and steel coupons was determined according to a previously published method with slight modifications (Brown et al., 2014). Briefly, $200 \mu \mathrm{L}$ of CEB broth containing C. jejuni ( 2.0 Log CFU) was added to 96-well polystyrene plates or on steel coupons kept in 24-well polystyrene plates and incubated for $48 \mathrm{~h}$ at 20 or $37^{\circ} \mathrm{C}$ under aerobic condition to facilitate biofilm formation. The biofilm formation was determined by 2, 3, 5Triphenyltetrazolium chloride (TTC) staining at $24 \mathrm{~h}$ intervals. After staining, TTC solution was removed followed by air-drying and bound TTC dye was dissolved in $20 \%$ acetone in ethanol, and the $A_{500}$ value of the solution was measured. A similar procedure was used to determine $C$. jejuni biofilm formation in broth containing $5 \%$ chicken meat juice.

\section{Determination of Sub-Inhibitory Concentrations and Minimum Bactericidal Concentrations of Phytochemicals}

The sub-inhibitory concentration (SIC) and minimum bactericidal concentration (MBC) of each phytochemical against C. jejuni was determined according to a previously described method (Upadhyay et al., 2017b; Wagle et al., 2017a,b). All three phytochemicals were purchased from Sigma-Aldrich (St. Louis, MO, United States). In brief, twofold dilutions of TC, EG, or CR in CEB (100 $\mu \mathrm{L} /$ well) were made in sterile 96-well polystyrene plates (Costar, Corning Incorporated, Corning, NY, United States) followed by inoculation with equal volume of C. jejuni $\left(10^{6} \mathrm{CFU} / \mathrm{mL}\right)$ and incubated at $37^{\circ} \mathrm{C}$ for $24 \mathrm{~h}$ under microaerophilic conditions. The growth of C. jejuni was determined by plating on Campylobacter Line Agar (CLA) plates (Line, 2001). The highest concentration of phytochemicals that did not inhibit bacterial growth was selected as the SIC for the study, whereas the lowest concentration of phytochemicals that reduced C. jejuni counts significantly ( $>2 \log _{10} \mathrm{CFU} / \mathrm{mL}$ ) was taken as MBC.

\section{Biofilm Inhibition and Inactivation Assays on Polystyrene Plates}

The ability of TC, EG, and CR in inhibiting C. jejuni biofilm formation on polystyrene plates was determined according to a previously published method (Reeser et al., 2007; Lu et al., 2012). Two hundred microliters of culture $(\sim 6.0$ Log CFU) was added to each well of a sterile 96-well polystyrene plate, followed by addition of SICs of TC, EG, or CR. The plates were incubated at 20 or $37^{\circ} \mathrm{C}$ for $48 \mathrm{~h}$. A similar procedure was followed to test the antibiofilm efficacy of phytochemicals in the presence of $5 \%$ chicken meat juice. The biofilm formation was determined at $24 \mathrm{~h}$ intervals. At each time point, the spent medium was removed and the well was gently washed three times with BPD. The bacteria in the biofilms were removed using cell scrapper and plated on 
CLA plates. The biofilm associated C. jejuni were enumerated after incubation at $42^{\circ} \mathrm{C}$ for $48 \mathrm{~h}$.

The inactivation of mature C. jejuni biofilms by TC, EG and CR was determined as described previously (Kim et al., 2017). Briefly, C. jejuni ( 6.0 Log CFU, $200 \mu \mathrm{L})$ was allowed to form biofilm in 96 -well polystyrene plate at 20 or $37^{\circ} \mathrm{C}$ for $48 \mathrm{~h}$. After mature biofilm was formed, the inactivation was carried out with $200 \mu \mathrm{L}$ of TC $(18.91,37.82$, or $75.64 \mathrm{mM})$, EG $(15.22,30.45$, or $60.90 \mathrm{mM})$ or $\mathrm{CR}(16.64,33.28$, or $66.56 \mathrm{mM})$ in BPD for 1,5 , or $10 \mathrm{~min}$. The treatment solution was discarded and $200 \mu \mathrm{L}$ of Dey-Engley neutralizing broth (Difco Laboratories, Sparks, MD, United States) was added. The number of surviving C. jejuni in the biofilm was determined as described above. The study was repeated in the presence of $5 \%$ chicken meat juice.

\section{Preparation of Stainless-Steel Coupons}

A previously described method (Jeong and Frank, 1994) was used for the preparation of stainless-steel coupons (Type 304; diameter $5 / 8$ inch; no. 4 finish). Briefly, steel coupons were cleaned with acetone followed by washing in distilled water and soaking in $100 \%$ ethanol. Finally, steel coupons were rinsed with distilled water, subjected to air dry and autoclaved at $121^{\circ} \mathrm{C}$ for $15 \mathrm{~min}$.

\section{Biofilm Inhibition and Inactivation Assays on Stainless-Steel Coupons}

To determine the effect of TC, EG, and CR in inhibiting biofilm formation and inactivating mature biofilm on stainlesssteel, a published method was used with slight modifications (Trachoo et al., 2002). For the inhibition study, steel coupons were incubated with $1 \mathrm{~mL}$ of C. jejuni ( $2.0 \mathrm{Log}$ CFU) in $24-$ well polystyrene plates containing SICs of phytochemicals at 20 or $37^{\circ} \mathrm{C}$ for 48 h. C. jejuni counts in the biofilms on steel coupons were determined after washing three times with BPD at $24 \mathrm{~h}$ intervals.

For the inactivation of mature biofilm on steel coupons, mature biofilm was developed on steel coupons placed in 24well polystyrene plates containing C. jejuni $(\sim 6.0$ Log CFU) at 20 or $37^{\circ} \mathrm{C}$ for $48 \mathrm{~h}$. After biofilm formation, steel coupons were rinsed three times with $\mathrm{BPD}$ and transferred to new polystyrene plates and exposed to various doses of TC $(18.91,37.82$, or $75.64 \mathrm{mM}$ ), EG (15.22, 30.45, or $60.90 \mathrm{mM})$, or CR (16.64, 33.28 , or $66.56 \mathrm{mM}$ ) for 1,5 , or $10 \mathrm{~min}$. Following rinsing with $\mathrm{BPD}$, the steel coupons were placed in $50 \mathrm{~mL}$ centrifuged tubes containing $3 \times g$ sterile glass beads (diameter $2 \mathrm{~mm}$; Thermo Fisher Scientific, Carlsbad, CA, United States) and $10 \mathrm{~mL}$ of Dey-Engley neutralizing broth, and vortexed for $1 \mathrm{~min}$. The solution was serially diluted and plated on CLA. C. jejuni counts were enumerated after incubation of plates at $42^{\circ} \mathrm{C}$ for $48 \mathrm{~h}$. Similar inhibition and inactivation studies were conducted in the presence of $5 \%$ chicken meat juice in broth medium.

\section{Microscopic Examination of C. jejuni Biofilms}

Environmental scanning electron microscopy (ESEM) and confocal laser scanning microscopy (CLSM) were used to visualize the effect of TC, EG, and CR on biofilm architecture and the viability of C. jejuni in biofilms. C. jejuni (6 Log CFU) was inoculated on stainless-steel coupons and Lab-Tek twochamber (no. 1) borosilicate coverglass system (Nunc, Rochester, NY, United States) for ESEM and CLSM, respectively to develop biofilms at $37^{\circ} \mathrm{C}$ for 2 days, and were exposed to TC (18.91 mM), EG (15.22 $\mathrm{mM})$, or CR $(16.64 \mathrm{mM})$ for $10 \mathrm{~min}$. All the samples were rinsed with BPD before further processing. For ESEM, samples were fixed with $2.5 \%$ glutaraldehyde in $0.1 \mathrm{M}$ PIPES buffer for $1 \mathrm{~h}$, as described previously (Brown et al., 2014). After fixation, samples were rinsed three times with PIPES buffer and dehydrated in a series of ethanol solutions (at 30, 40, 50, 60, 70, 80,90 , and three times at $100 \%$ ) for at least $10 \mathrm{~min}$ for each step. The biofilms were dried and coated with gold using Emitech SC7620 sputter coater (Quorum Technologies, Ltd., East Sussex, United Kingdom) for 135 s. The coated biofilm samples were visualized using SE detectors at $10 \mathrm{kV}$ beam (Philips XL30 ESEM, FEI Company, Hillsboro, OR, United States). For the CLSM, the viability of $C$. jejuni in the biofilms were determined using FilmTracer ${ }^{\mathrm{TM}}$ Live/Dead Biofilm Viability Kit (Molecular probes, Eugene, OR, United States) according to a published method (Asakura et al., 2007). SYTO-9 and propidium iodide stains were used for the differential staining of live and dead cells. After staining for $20 \mathrm{~min}$, biofilms were visualized in each chamber using a hybrid detector at $63 \times$ objective in the Leica SP5 Confocal microscope (Leica Microsystems Inc., Buffalo Grove, IL, United States).

\section{Gene Expression Analysis of C. jejuni Exposed to Phytochemical Treatments}

The effect of TC, EG, and CR on the transcription of C. jejuni genes essential for biofilm formation was determined using real-time quantitative PCR (RT-qPCR) (Upadhyay et al., 2017b; Wagle et al., 2017a,b). Briefly, C. jejuni ( 6.0 Log CFU/mL) was incubated in the presence or absence of SICs of TC, EG or CR at $37^{\circ} \mathrm{C}$ for $12 \mathrm{~h}$. The total RNA was extracted using RNA mini kit (Invitrogen, Carlsbad, CA, United States) and complementary DNAs were prepared using iScript cDNA synthesis kit (Bio-Rad Laboratories, Inc., CA, United States). The primers were designed using Primer 3 Software (National Center for Biotechnology Information, Bethesda, MD, United States) and obtained from Integrated DNA Technologies, Inc. (Coralville, IA, United States) (Table 1). The specificity of primer was tested using NCBI-Primer BLAST, melt curve analysis and in silico PCR (Bikandi et al., 2004). The amplified products were detected by using SYBR Green reagents (Bio-Rad Laboratories, Inc.). The 16s rRNA gene was used as the endogenous control and comparative critical threshold $(\Delta \Delta \mathrm{Ct})$ method was employed to analyze relative expressions of candidate genes on Quant Studio 3 real-time PCR system (Applied Biosystems, Thermo Fisher Scientific).

\section{Proteomic Analysis of C. jejuni in Biofilms Exposed to Phytochemical Treatments}

The effect of TC, EG, and CR on the proteome of C. jejuni in the biofilms was determined using liquid chromatography with tandem mass spectrometry (LC-MS/MS) as described 
TABLE 1 | Primers used for gene expression analysis using real-time quantitative PCR.

\begin{tabular}{lll}
\hline Gene with & Primer & Sequence (5' -3') \\
Accession no. & & \\
\hline 16S-rRNA & Forward Reverse & 5'-ATAAGCACCGGCTAACTCCG-3' \\
(NC_002163.1) & & 5'-TTACGCCCAGTGATTCCGAG-3' \\
flaA (NC_002163.1) & Forward Reverse & 5'-AGCGTTGCAAAACCTGTGG-3' \\
(NC_002163.1) & & 5'-ATGAGTAGCGCAGGAAGTGG-3' \\
flaB (NC_002163.1) & Forward Reverse & 5'-AGCGTTGCAAAACCTGTGG-3' \\
(NC_002163.1) & & 5'-ATGAGTAGCGCAGGAAGTGG-3' \\
flaG (NC_002163.1) & Forward Reverse & 5'-AGAACAAGTGAGACACAGGCT-3' \\
(NC_002163.1) & & 5'-TTGCTGTCCATCATCGCCTT-3' \\
flgA (NC_002163.1) & Forward Reverse & 5'-TTTGCACGAATCCTTCGCC-3' \\
(NC_002163.1) & & 5'-TCGGGGTTTAAGCGAAGCA-3' \\
peb4 (NC_002163.1) & Forward Reverse & 5'-AAGGTGGTGAGCTTGGTTGG-3' \\
(NC_002163.1) & & 5'-TTAAGCGCGAAAGCAGCATC-3' \\
waaF (NC_002163.1) & Forward Reverse & 5'-CCTGGTGCAAGCTTGGAAG-3' \\
(NC_002163.1) & & 5'-TTGTTCGGCTITCCTGCAC-3' \\
CosR (NC_002163.1) & Forward Reverse & 5'-TCAGGTTCTTCCCAGATGGC-3' \\
(NC_002163.1) & & 5'-CGCACTTAGCAAGACATTCGG-3' \\
ahpC (NC_002163.1) & Forward Reverse & 5'-AGTTCGCCATGCTGTGGTTA-3' \\
(NC_002163.1) & & 5'-CCTGCAGGACAAACTTCACC-3' \\
luxS (NC_002163.1) & Forward Reverse & 5'-AGTGTTGCAAAAGCTTGGGA-3' \\
(NC_002163.1) & & 5'-GCATTGCACAAGTTCCGCAT-3' \\
\hline & & \\
\hline & & \\
\hline
\end{tabular}

previously (Miyamoto et al., 2015). Briefly, C. jejuni ( 6.0 Log $\mathrm{CFU} / \mathrm{mL}$ ) was incubated in the presence or absence of SICs of phytochemicals and allowed to develop biofilms at $37^{\circ} \mathrm{C}$ for $48 \mathrm{~h}$. Following washing with BPD buffer, proteins were extracted using B-Per ${ }^{\circledR}$ bacterial protein extraction reagent (Thermo Fisher Scientific) and subjected to SDS-PAGE (4-12\% Bis-Tris protein gel, Thermo Fisher Scientific). Each lane of gel was excised and destained with 50\% acetonitrile in ammonium bicarbonate (Thermo Fisher Scientific) for $45 \mathrm{~min}$ and vacuum dried for $10 \mathrm{~min}$. The protein extracts were treated with dithiothreitol $(1.5 \mathrm{mg} / \mathrm{mL}$ in $25 \mathrm{mM}$ ammonium bicarbonate; Bio-Rad) and reduced with iodoacetamide $(37 \mathrm{mg} / \mathrm{mL}$ in ammonium bicarbonate; Bio-Rad) for $1 \mathrm{~h}$. Following removal of iodoacetamide, the proteins were digested with trypsin (20 ng per $\mu \mathrm{L}$ in $25 \mathrm{mM}$ ammonium bicarbonate) and incubated overnight at $37^{\circ} \mathrm{C}$. The resultant peptides were analyzed by LC-MS/MS technique using Agilent 1200 series microflow HPLC coupled to a Bruker AmaZon-SL quadrupole ion trap mass spectrometer (Bruker Daltonics Inc., Billerica, MA, United States) with a captive spray ionization source. The proteins were identified by matching MS/MS spectra to protein sequences of C. jejuni available at the uniprot.org using in house MASCOT software (Matrix Science Inc., Boston, MA, United States) (Perkins et al., 1999). The proteins were identified based on $<5 \%$ false discovery rate using at least 2 unique peptides from a protein.

\section{Statistical Analyses}

A completely randomized design was used in the study with duplicate samples and the study was repeated three times. The data for each treatment and control were pooled from three independent trials within the same study before analysis. Bacterial counts were logarithmic transferred to maintain the homogeneity of variance (Byrd et al., 2001). The data of inhibition and inactivation assays were analyzed by using PROC MIXED procedure in the SAS version 9.3 software (SAS Institute Inc., Cary, NC, United States) and the treatment means were separated by least-square means analysis at $P<0.05$ for statistical difference. The gene expression data were analyzed by using PROC MIXED procedure in the SAS and Student's $t$-test was used for comparisons between treatment and controls. For the proteomic analysis, Scaffold Proteome Software version 4.8 (Proteome Software Inc., Portland, OR, United States) was used to analyze MASCOT files and differentially expressed proteins between treated and un-treated biofilms were determined using Student's $t$-test.

\section{RESULTS}

\section{Sub-Inhibitory Concentrations and Minimum Bactericidal Concentrations of TC, EG, and CR Against C. jejuni}

The SICs of phytochemicals were determined based on growth curve analysis (data not shown). We observed that $0.75 \mathrm{mM}$ $(0.01 \% \mathrm{v} / \mathrm{v})$ of TC, $0.61 \mathrm{mM}(0.01 \% \mathrm{v} / \mathrm{v})$ of $\mathrm{EG}$ and $0.13 \mathrm{mM}(0.002 \% \mathrm{v} / \mathrm{v})$ of CR were the highest concentration of phytochemicals that did not reduce the growth of C. jejuni and were selected as the respective SIC for the study. Similarly, the lowest concentrations that reduced $C$. jejuni counts significantly were $2.27 \mathrm{mM}(0.03 \%)$ for TC, $1.83 \mathrm{mM}(0.03 \%)$ for EG and $0.26 \mathrm{mM}(0.004 \%)$ for CR and these doses were taken as MBC.

\section{Effect of Chicken Juice on C. jejuni Biofilm Formation on Polystyrene Plates and Stainless-Steel Coupons}

Figure 1 shows the C. jejuni biofilm formation on polystyrene plates and stainless-steel coupons in the presence or absence of $5 \%$ chicken meat juice. The presence of chicken juice significantly enhanced C. jejuni biofilm formation by $\sim$ twofold at both temperatures on both surfaces. In addition, the absorbance (indicator of adhered and metabolically active C. jejuni) was significantly higher in the $48 \mathrm{~h}$ biofilms developed at $37^{\circ} \mathrm{C}$ than at $20^{\circ} \mathrm{C}$.

\section{Effect of Sub-Inhibitory Concentrations of TC, EG, and CR on C. jejuni Biofilm Formation on Polystyrene Plates and Stainless-Steel Coupons}

Figure 2 presents the effect of TC, EG, and CR on C. jejuni biofilm formation on polystyrene plates at 20 and $37^{\circ} \mathrm{C}$ in the presence and absence of chicken juice. C. jejuni biofilm developed in broth medium had $\sim 7.3$ and $8 \mathrm{Log} \mathrm{CFU} / \mathrm{mL}$ of pathogen count at $20^{\circ} \mathrm{C}$ (Figure $2 \mathbf{A}$ ) and $37^{\circ} \mathrm{C}$ (Figure 2B), respectively, after $48 \mathrm{~h}$ of incubation. The presence of SICs of TC, EG, and CR significantly reduced C. jejuni counts in the biofilm developed at $20^{\circ} \mathrm{C}$ by $\sim 0.5$ and $0.7 \log \mathrm{CFU} / \mathrm{mL}$, respectively, at 24 and $48 \mathrm{~h}$ as compared to the control. At 
A

(Polystyrene plates)

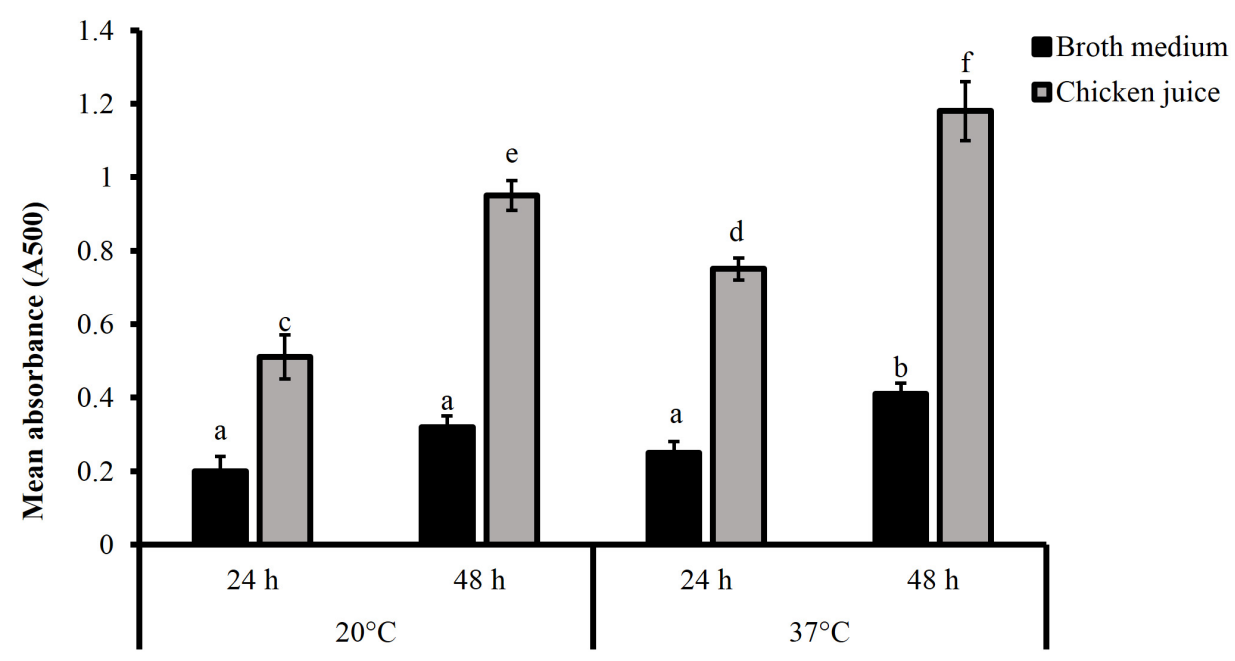

C. jejuni biofilm formation at different times and temperatures

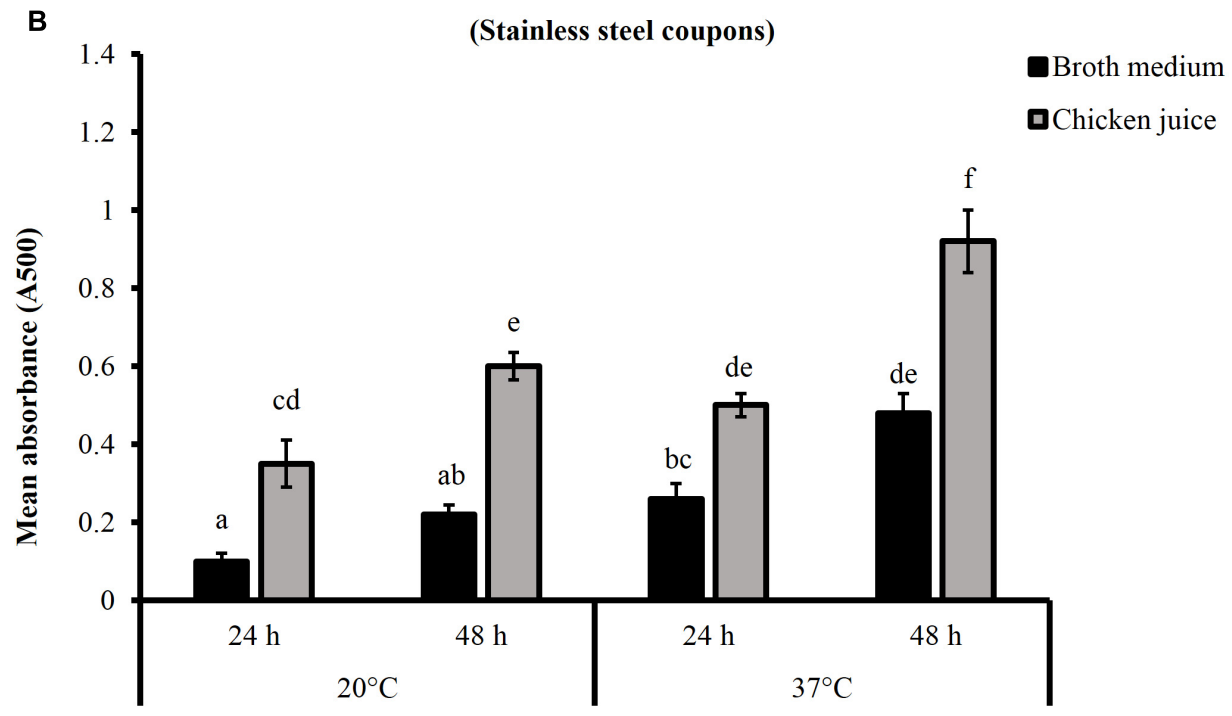

C. jejuni biofilm formation at different times and temperatures

FIGURE 1 | Campylobacter jejuni biofilm formation on polystyrene plates $\mathbf{( A )}$ and stainless-steel coupons $\mathbf{( B )}$ at 20 and $37^{\circ} \mathrm{C}$. Error bars represent SEM $(n=6)$. C. jejuni ( 6.0 Log CFU/mL) in the presence or absence of $5 \%$ chicken meat juice was incubated to form biofilm. The biofilm formation was determined by $T$ TC staining at $24 \mathrm{~h}$ interval. Different letters indicate the statistical difference across time or temperatures $(P<0.05)$.

$37^{\circ} \mathrm{C}$, the reduction was $\sim 0.56 \mathrm{Log} \mathrm{CFU} / \mathrm{mL}$ at both time points $(P<0.05)$. Similar results were observed in the presence of chicken meat juice at both temperatures (Figures 2C,D) where the three phytochemicals exerted an inhibitory effect and reduced C. jejuni biofilm formation by $\sim 0.5 \mathrm{Log} \mathrm{CFU} / \mathrm{mL}$. Carvacrol was the most effective treatment and reduced $C$. jejuni in the biofilm by $\sim 1.5$ and $\sim 0.75 \mathrm{Log} \mathrm{CFU} / \mathrm{mL}$, respectively, at $20^{\circ} \mathrm{C}$ and $37^{\circ} \mathrm{C}$ at the end of $48 \mathrm{~h}$ as compared to respective controls (Figures 2C,D).
The effect of TC, EG, and CR in inhibiting C. jejuni biofilm formation on stainless-steel coupons is shown in Figure 3. All phytochemicals reduced $C$. jejuni in the biofilm by $\sim 0.6$ and $\sim 0.45 \mathrm{Log} \mathrm{CFU} / \mathrm{mL}$, respectively, at 20 (Figure $3 \mathrm{~A}$ ) and $37^{\circ} \mathrm{C}$ (Figure 3B) at both time points $(P<0.05)$. Similar reductions were observed when biofilm was developed in the presence of $5 \%$ chicken meat juice on steel coupons (Figures 3C,D). Although phytochemicals were effective in reducing C. jejuni counts as compared to respective controls at 24 and $48 \mathrm{~h}$, the 


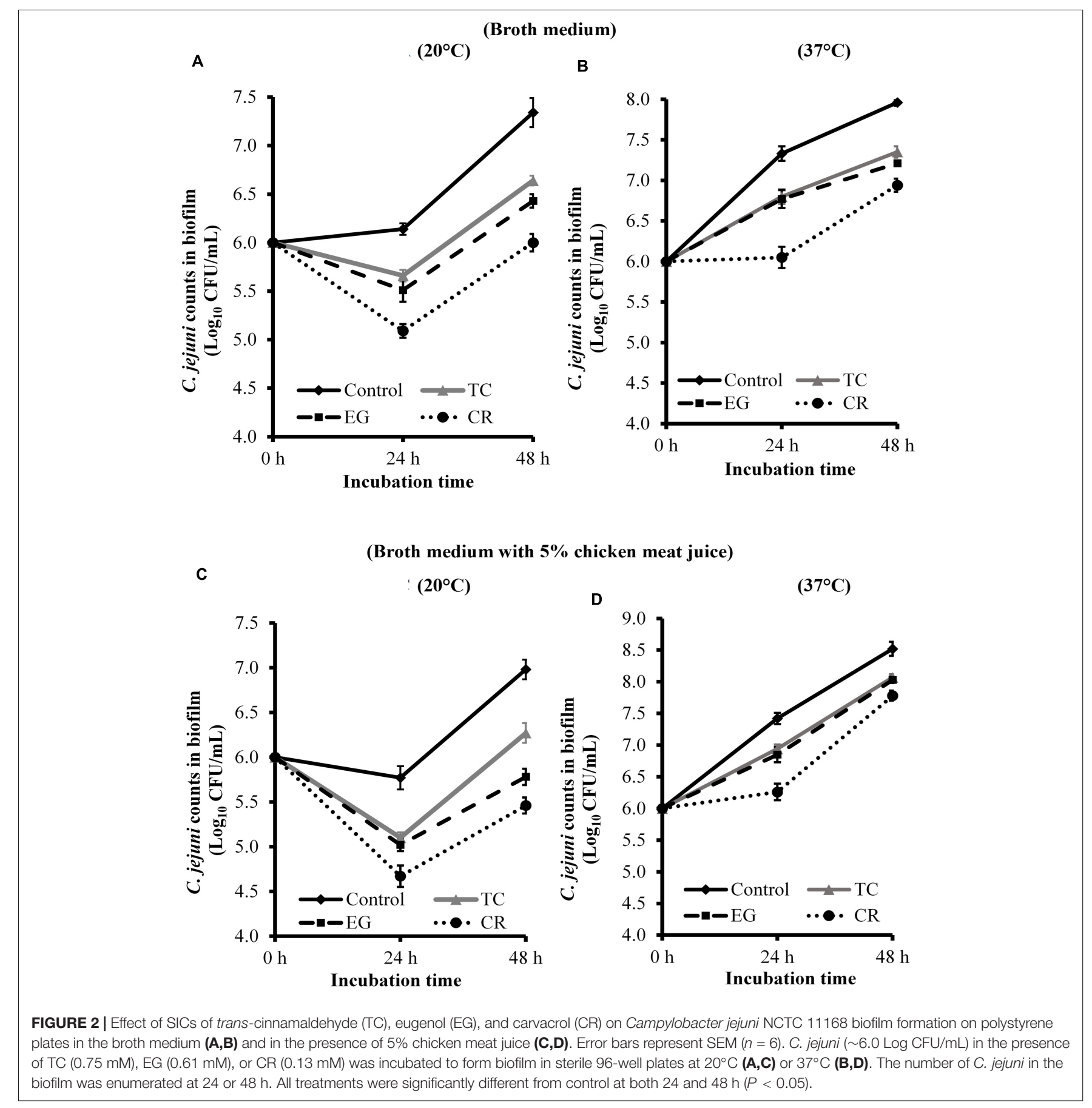

phytochemicals did not inhibit the growth of $C$. jejuni biofilm at $48 \mathrm{~h}$ as compared to $24 \mathrm{~h}$ except at $37^{\circ} \mathrm{C}$ in CEB (Figure 3B).

\section{Effect of TC, EG, and CR on Mature C. jejuni Biofilms Developed on Polystyrene Plates and Stainless-Steel Coupons}

The efficacy of TC, EG and CR in inactivating mature C. jejuni biofilms on polystyrene plates and steel coupons is shown in
Tables 2, 3, respectively. The number of $C$. jejuni recovered from control (biofilms not subjected to treatments) on polystyrene plates was $\sim 7.8$ and $\sim 8.4 \log \mathrm{CFU} / \mathrm{mL}$, respectively, at 20 and $37^{\circ} \mathrm{C}$ in the broth medium (Table 2). Similar counts were observed in the presence of $5 \%$ chicken meat juice on polystyrene plates $(P>0.05)$. At $20^{\circ} \mathrm{C}$ on polystyrene, highest doses of TC (75.64 mM;1\%), EG (60.90 mM;1\%), and $\mathrm{CR}(66.56 \mathrm{mM} ; 1 \%)$ reduced the counts of $C$. jejuni to below detection limit (reductions $>7.0 \mathrm{Log} C F U / \mathrm{mL}$ ) in the broth medium within $1 \mathrm{~min}$ of exposure time. Lower doses 


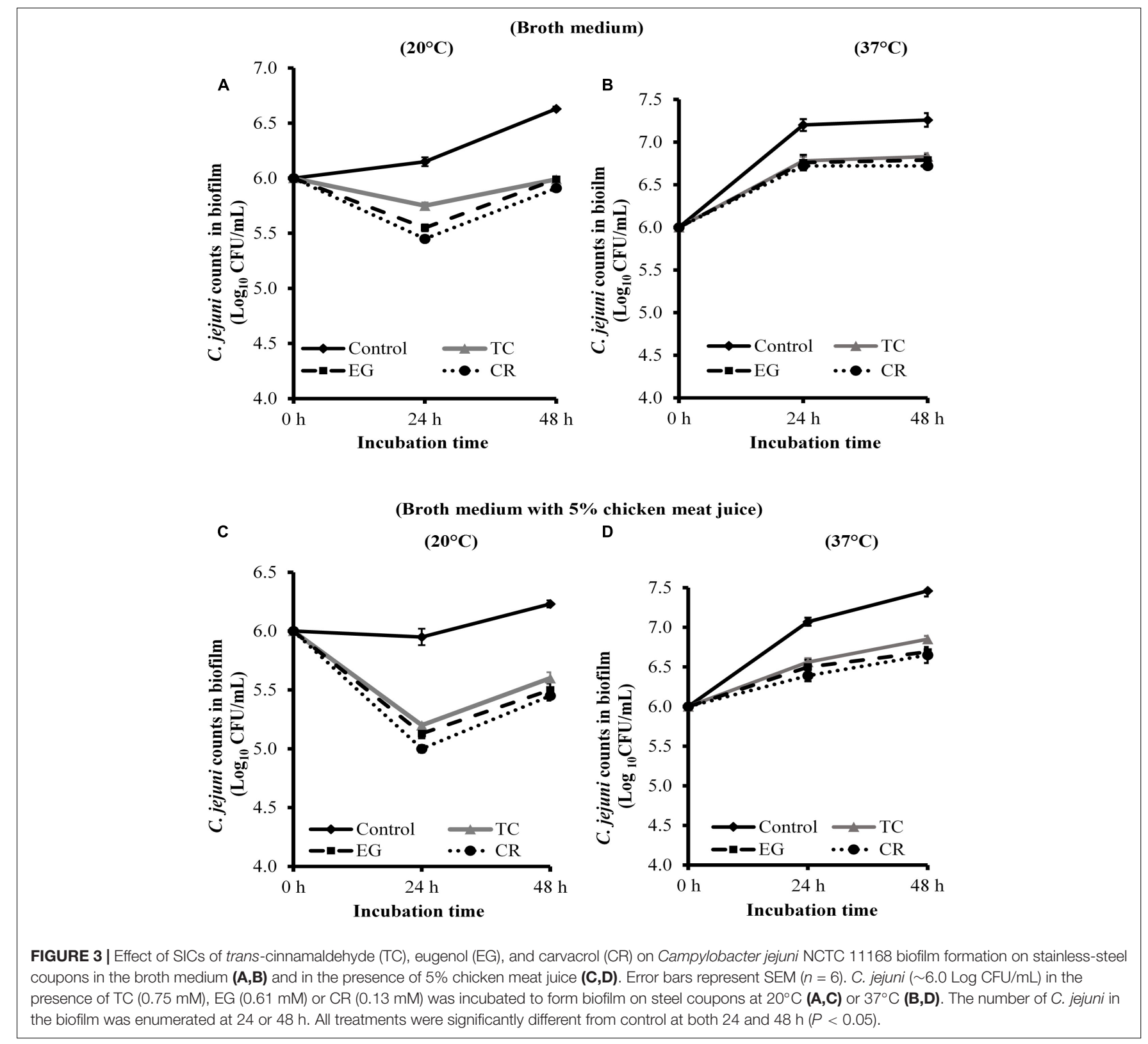

of TC (18.91 and $37.82 \mathrm{mM}$, corresponds to 0.25 and $0.5 \%$, respectively), EG (15.22 and $30.45 \mathrm{mM} ; 0.25$ and $0.5 \%$ ), and CR (16.64 and $33.28 \mathrm{mM} ; 0.25$ and $0.5 \%$ ) reduced C. jejuni in the biofilms in a range from 3.2 to $3.8 \mathrm{Log} \mathrm{CFU} / \mathrm{mL}$ in $10 \mathrm{~min}$. The phytochemicals were effective in inactivating C. jejuni biofilms in the presence of chicken juice as well. For example, in the presence of chicken juice at $20^{\circ} \mathrm{C}, 66.56 \mathrm{mM}$ $\mathrm{CR}$ reduced $C$. jejuni counts by $6.69 \mathrm{Log} \mathrm{CFU} / \mathrm{mL}$ (most effective treatment) followed by $33.28 \mathrm{mM}$ CR or $60.90 \mathrm{mM}$ EG (reductions $\sim 3.8 \mathrm{Log} \mathrm{CFU} / \mathrm{mL}$ ) in $10 \mathrm{~min}$ exposure time (Table 2). At $37^{\circ} \mathrm{C}$ in the broth medium, $60.90 \mathrm{mM} \mathrm{EG}$ or $66.56 \mathrm{mM} \mathrm{CR}$ was the most effective in reducing C. jejuni counts by $\sim 3.84 \log \mathrm{CFU} / \mathrm{mL}$ at the end of $10 \mathrm{~min}$. The reductions were similar in the presence of chicken juice where TC (75.64 mM), EG (60.90 mM), and CR (66.56 mM) reduced the counts by $1.64,4.11$, and $4.88 \mathrm{Log} \mathrm{CFU} / \mathrm{mL}$, respectively, in 10 min (Table 2).

On stainless-steel coupons, C. jejuni counts in the control biofilms developed at $20^{\circ} \mathrm{C}$ were $\sim 6.3 \mathrm{Log} \mathrm{CFU} / \mathrm{mL}$ (Table 3). The biofilms developed at $37^{\circ} \mathrm{C}$ had $\sim 7.8 \mathrm{Log} \mathrm{CFU} / \mathrm{mL}$ of C. jejuni present. In the biofilms developed at $20^{\circ} \mathrm{C}$ in the broth medium, EG $(30.45,60.90 \mathrm{mM})$ or CR $(16.64,33.28$, and $66.56 \mathrm{mM}$ ) reduced the counts of $C$. jejuni to below detection limit as early as 1 min of treatment time. TC (37.82, $75.64 \mathrm{mM}$ ) treatments reduced the counts to below detection limit within $5 \mathrm{~min}$ of treatment. The lowest dose (15.22 mM) of EG also reduced the counts below detection within $5 \mathrm{~min}$ (reductions > $6.25 \mathrm{Log} \mathrm{CFU} / \mathrm{mL}$ ) whereas $18.91 \mathrm{mM} \mathrm{TC}$ significantly reduced the counts by $\sim 4.5 \mathrm{Log} \mathrm{CFU} / \mathrm{mL}$ in $10 \mathrm{~min}$ exposure time. In the presence of $5 \%$ chicken meat juice, 
TABLE 2 | Effect of trans-cinnamaldehyde (TC; 18.91, 37.82, 75.64 mM), eugenol (EG; 15.22, 30.45, 60.90 mM), and carvacrol (CR; 16.64, $33.28,66.56$ mM) on mature Campylobacter jejuni NCTC 11168 biofilm formed on polystyrene microtiter plates at $20^{\circ} \mathrm{C}$ or $37^{\circ} \mathrm{C}$ in the broth medium and in the presence of chicken meat juice $(n=6)$.

\begin{tabular}{|c|c|c|c|c|c|c|c|c|c|c|c|c|c|}
\hline \multirow{3}{*}{\multicolumn{2}{|c|}{ Treatments }} & \multicolumn{6}{|c|}{$20^{\circ} \mathrm{C}$} & \multicolumn{6}{|c|}{$37^{\circ} \mathrm{C}$} \\
\hline & & \multicolumn{3}{|c|}{ Broth medium } & \multicolumn{3}{|c|}{ Broth $+5 \%$ chicken juice } & \multicolumn{3}{|c|}{ Broth medium } & \multicolumn{3}{|c|}{ Broth $+5 \%$ chicken juice } \\
\hline & & $1 \mathrm{~min}$ & $5 \mathrm{~min}$ & $10 \min$ & $1 \mathrm{~min}$ & $5 \mathrm{~min}$ & $10 \mathrm{~min}$ & $1 \mathrm{~min}$ & $5 \mathrm{~min}$ & $10 \mathrm{~min}$ & $1 \mathrm{~min}$ & $5 \mathrm{~min}$ & $10 \mathrm{~min}$ \\
\hline \multicolumn{2}{|c|}{ Control } & $8.10 \pm 0.10^{a *}$ & $7.79 \pm 0.08^{\mathrm{a}}$ & $7.78 \pm 0.08^{\mathrm{a}}$ & $7.81 \pm 0.05^{a}$ & $7.81 \pm 0.05^{\mathrm{a}}$ & $7.81 \pm 0.05^{a}$ & $8.35 \pm 0.11^{a}$ & $8.44 \pm 0.10^{a}$ & $8.39 \pm 0.09^{a}$ & $8.59 \pm 0.04^{a}$ & $8.66 \pm 0.03^{a}$ & $8.63 \pm 0.04^{a}$ \\
\hline \multirow[t]{3}{*}{$\mathrm{TC}(\mathrm{mM})$} & 18.91 & $6.80 \pm 0.09^{b}$ & $5.63 \pm 0.08^{b}$ & $4.54 \pm 0.07^{b}$ & $6.69 \pm 0.11^{b}$ & $6.15 \pm 0.04^{b}$ & $5.14 \pm 0.04^{b}$ & $7.80 \pm 0.05^{b}$ & $7.78 \pm 0.05^{b}$ & $7.54 \pm 0.04^{b}$ & $8.38 \pm 0.06^{\mathrm{ab}}$ & $8.26 \pm 0.03^{b}$ & $7.98 \pm 0.04^{b}$ \\
\hline & 37.82 & $6.41 \pm 0.07^{c}$ & $4.32 \pm 0.09^{c}$ & $4.00 \pm 0.06^{\mathrm{cd}}$ & $6.45 \pm 0.14^{b}$ & $5.19 \pm 0.06^{c}$ & $4.89 \pm 0.03^{b c}$ & $7.62 \pm 0.05^{b c}$ & $7.53 \pm 0.04^{b}$ & $7.39 \pm 0.07^{b}$ & $7.67 \pm 0.04^{d}$ & $7.68 \pm 0.06^{c}$ & $7.60 \pm 0.14^{c}$ \\
\hline & 75.64 & $N D^{e}$ & $N D^{d}$ & $N D^{e}$ & $5.27 \pm 0.06^{c d}$ & $4.89 \pm 0.06^{c}$ & $4.59 \pm 0.07^{c}$ & $7.68 \pm 0.12^{b}$ & $5.79 \pm 0.09^{d}$ & $5.61 \pm 0.07^{d}$ & $7.52 \pm 0.03^{d}$ & $7.36 \pm 0.05^{c}$ & $6.99 \pm 0.19^{d}$ \\
\hline \multirow[t]{3}{*}{$E G(m M)$} & 15.22 & $6.58 \pm 0.05^{b c}$ & $5.40 \pm 0.09^{b}$ & $4.52 \pm 0.06^{b}$ & $6.68 \pm 0.09^{b}$ & $6.20 \pm 0.05^{b}$ & $5.00 \pm 0.07^{b c}$ & $7.49 \pm 0.06^{b c}$ & $6.47 \pm 0.49^{c}$ & $6.34 \pm 0.10^{c}$ & $8.09 \pm 0.08^{b c}$ & $7.66 \pm 0.16^{c}$ & $6.75 \pm 0.16^{\text {de }}$ \\
\hline & 30.45 & $6.09 \pm 0.07^{d}$ & $4.34 \pm 0.05^{c}$ & $3.91 \pm 0.09^{d}$ & $6.38 \pm 0.04^{b}$ & $5.11 \pm 0.05^{c}$ & $4.82 \pm 0.02^{\mathrm{C}}$ & $7.57 \pm 0.11^{\mathrm{bc}}$ & $5.59 \pm 0.10^{d}$ & $4.95 \pm 0.16^{e}$ & $7.84 \pm 0.25^{\mathrm{cd}}$ & $6.16 \pm 0.04^{e}$ & $5.72 \pm 0.07^{f}$ \\
\hline & 60.90 & $N D^{e}$ & $N D^{d}$ & $N D^{e}$ & $5.01 \pm 0.06^{\mathrm{de}}$ & $4.89 \pm 0.03^{c}$ & $3.93 \pm 0.08^{d}$ & $7.31 \pm 0.08^{c}$ & $5.16 \pm 0.21^{\mathrm{e}}$ & $4.55 \pm 0.27^{\mathrm{fg}}$ & $6.67 \pm 0.38^{\mathrm{e}}$ & $5.18 \pm 0.11^{f}$ & $4.52 \pm 0.20^{g}$ \\
\hline \multirow[t]{3}{*}{$\mathrm{CR}(\mathrm{mM})$} & 16.64 & $6.37 \pm 0.07^{c d}$ & $5.25 \pm 0.11^{b}$ & $4.33 \pm 0.07^{b c}$ & $5.44 \pm 0.01^{c}$ & $5.16 \pm 0.04^{c}$ & $4.80 \pm 0.08^{\mathrm{C}}$ & $6.94 \pm 0.17^{d}$ & $6.30 \pm 0.11^{c}$ & $6.07 \pm 0.05^{c}$ & $6.91 \pm 0.16^{e}$ & $6.76 \pm 0.05^{d}$ & $6.46 \pm 0.09^{e}$ \\
\hline & 33.28 & $6.14 \pm 0.07^{\mathrm{cd}}$ & $4.26 \pm 0.09^{c}$ & $3.98 \pm 0.07^{\mathrm{cd}}$ & $4.73 \pm 0.09^{e}$ & $4.49 \pm 0.05^{d}$ & $4.03 \pm 0.11^{d}$ & $5.87 \pm 0.15^{e}$ & $5.55 \pm 0.05^{d}$ & $4.89 \pm 0.09^{e f}$ & $5.41 \pm 0.12^{f}$ & $5.18 \pm 0.05^{f}$ & $4.50 \pm 0.09^{9}$ \\
\hline & 66.56 & $N D^{e}$ & $N D^{d}$ & $N D^{e}$ & $3.30 \pm 0.32^{f}$ & $3.11 \pm 0.07^{e}$ & $1.12 \pm 0.26^{e}$ & $5.76 \pm 0.09^{e}$ & $5.07 \pm 0.25^{e}$ & $4.46 \pm 0.099$ & $4.90 \pm 0.07^{9}$ & $4.77 \pm 0.13^{9}$ & $3.75 \pm 0.13^{h}$ \\
\hline
\end{tabular}

The biofilms were exposed to phytochemical treatment for 1,5 , or 10 min. Values (Log CFU/mL) presented as mean \pm standard error of the mean. *The different superscripts within columns differ significantly at $P<0.05$. ND: not detectable below 1 Log CFU/mL.

TABLE 3 | Effect of trans-cinnamaldehyde (TC; 18.91, 37.82, 75.64 mM), eugenol (EG; 15.22, 30.45, 60.90 mM), and carvacrol (CR; 16.64, 33.28, 66.56 mM) on mature Campylobacter jejuni NCTC 11168 biofilms formed on stainless-steel coupons at $20^{\circ} \mathrm{C}$ or $37^{\circ} \mathrm{C}$ in the broth medium and in the presence of chicken meat juice $(n=6)$.

\begin{tabular}{|c|c|c|c|c|c|c|c|c|c|c|c|c|c|}
\hline \multicolumn{8}{|c|}{$20^{\circ} \mathrm{C}$} & \multicolumn{6}{|c|}{$37^{\circ} \mathrm{C}$} \\
\hline \multirow{2}{*}{\multicolumn{2}{|c|}{ Treatments }} & \multicolumn{3}{|c|}{ Broth medium } & \multicolumn{3}{|c|}{ Broth $+5 \%$ chicken juice } & \multicolumn{3}{|c|}{ Broth medium } & \multicolumn{3}{|c|}{ Broth $+5 \%$ chicken juice } \\
\hline & & $1 \mathrm{~min}$ & $5 \mathrm{~min}$ & $10 \mathrm{~min}$ & $1 \mathrm{~min}$ & $5 \mathrm{~min}$ & $10 \mathrm{~min}$ & $1 \mathrm{~min}$ & $5 \mathrm{~min}$ & $10 \mathrm{~min}$ & $1 \mathrm{~min}$ & $5 \mathrm{~min}$ & $10 \mathrm{~min}$ \\
\hline \multicolumn{2}{|c|}{ Control } & $6.38 \pm 0.11^{a *}$ & $6.24 \pm 0.09^{a}$ & $6.35 \pm 0.05^{a}$ & $6.08 \pm 0.07^{\mathrm{a}}$ & $6.00 \pm 0.04^{a}$ & $6.05 \pm 0.03^{a}$ & $7.91 \pm 0.10^{a}$ & $7.84 \pm 0.03^{a}$ & $7.88 \pm 0.05^{\mathrm{a}}$ & $7.79 \pm 0.08^{\mathrm{a}}$ & $7.89 \pm 0.09^{a}$ & $7.75 \pm 0.07^{\mathrm{a}}$ \\
\hline \multirow[t]{3}{*}{ TC (mM) } & 18.91 & $3.62 \pm 0.08^{b}$ & $3.34 \pm 0.06^{b}$ & $1.85 \pm 0.08^{b}$ & $4.80 \pm 0.07^{b}$ & $4.23 \pm 0.04^{b}$ & $3.65 \pm 0.06^{b}$ & $6.11 \pm 0.08^{b}$ & $5.70 \pm 0.10^{b}$ & $5.05 \pm 0.08^{b}$ & $6.43 \pm 0.04^{b}$ & $6.12 \pm 0.05^{b}$ & $5.80 \pm 0.07^{b}$ \\
\hline & 37.82 & $1.77 \pm 0.04^{\mathrm{C}}$ & $N D^{C}$ & $N D^{C}$ & $2.11 \pm 0.12^{\mathrm{c}}$ & $1.56 \pm 0.22^{\mathrm{c}}$ & $N D^{c}$ & $5.21 \pm 0.05^{\mathrm{C}}$ & $5.00 \pm 0.07^{\circ}$ & $4.15 \pm 0.07^{c d}$ & $5.96 \pm 0.08^{c}$ & $5.71 \pm 0.04^{c}$ & $5.31 \pm 0.03^{c}$ \\
\hline & 75.64 & $N D^{d}$ & $N D^{C}$ & $\mathrm{ND}^{\mathrm{C}}$ & $1.10 \pm 0.20^{d}$ & $N D^{e}$ & $N D^{c}$ & $5.01 \pm 0.06^{c}$ & $4.30 \pm 0.08^{d}$ & $3.85 \pm 0.07^{d}$ & $5.55 \pm 0.07^{d}$ & $5.29 \pm 0.08^{d}$ & $4.94 \pm 0.12^{d}$ \\
\hline \multirow[t]{3}{*}{$\mathrm{EG}(\mathrm{mM})$} & 15.22 & $1.59 \pm 0.09^{c}$ & $\mathrm{ND}^{\mathrm{C}}$ & $N D^{c}$ & $2.00 \pm 0.11^{\mathrm{c}}$ & $1.02 \pm 0.17^{d}$ & $\mathrm{ND}^{\mathrm{C}}$ & $5.76 \pm 0.03^{b}$ & $4.95 \pm 0.08^{c}$ & $4.33 \pm 0.06^{c}$ & $6.19 \pm 0.09^{b c}$ & $5.58 \pm 0.07^{c d}$ & $5.13 \pm 0.09^{c d}$ \\
\hline & 30.45 & $N D^{d}$ & $\mathrm{ND}^{\mathrm{C}}$ & $N D^{C}$ & $1.03 \pm 0.13^{d}$ & $N D^{e}$ & $N D^{c}$ & $4.13 \pm 0.09^{d}$ & $3.06 \pm 0.09^{e}$ & $1.10 \pm 0.06^{f}$ & $5.33 \pm 0.05^{d}$ & $3.26 \pm 0.07^{e}$ & $1.88 \pm 0.15^{\mathrm{e}}$ \\
\hline & 60.90 & $N D^{d}$ & $\mathrm{ND}^{\mathrm{C}}$ & $N D^{C}$ & $N D^{e}$ & $N D^{e}$ & $\mathrm{ND}^{\mathrm{C}}$ & $N D^{f}$ & $N D^{f}$ & NDg & $4.14 \pm 0.15^{f}$ & $3.20 \pm 0.05^{e}$ & $N D^{f}$ \\
\hline \multirow[t]{3}{*}{ CR (mM) } & 16.64 & $N D^{d}$ & $\mathrm{ND}^{\mathrm{C}}$ & $N D^{C}$ & $1.80 \pm 0.26^{c}$ & $1.21 \pm 0.19^{d}$ & $N D^{c}$ & $3.21 \pm 0.04^{\mathrm{e}}$ & $2.94 \pm 0.10^{e}$ & $1.95 \pm 0.10^{\mathrm{e}}$ & $4.71 \pm 0.06^{e}$ & $3.39 \pm 0.27^{e}$ & $2.25 \pm 0.16^{\mathrm{e}}$ \\
\hline & 33.28 & $N D^{d}$ & $\mathrm{ND}^{\mathrm{C}}$ & $N D^{c}$ & $N D^{e}$ & $N D^{e}$ & $N D^{c}$ & $N D^{f}$ & $N D^{f}$ & NDg & $2.58 \pm 0.06^{g}$ & $1.66 \pm 0.36^{f}$ & $N D^{f}$ \\
\hline & 66.56 & $N D^{d}$ & $N^{c}$ & $N D^{c}$ & $N D^{e}$ & $N D^{e}$ & $N D^{c}$ & $N D^{f}$ & $N D^{f}$ & $N D^{g}$ & $N D^{h}$ & $N D^{g}$ & $N D^{f}$ \\
\hline
\end{tabular}

The biofilms were exposed to phytochemical treatments for 1, 5, or $10 \mathrm{~min}$. Values (Log CFU/mL) presented as mean \pm standard error of the mean. ${ }^{*}$ The different superscripts within columns differ significantly at $P<0.05$. ND: not detectable below $1 \mathrm{Log} C F U / \mathrm{mL}$. 
the lowest dose of TC $(18.91 \mathrm{mM})$ reduced $C$. jejuni counts significantly by $2.4 \mathrm{Log} \mathrm{CFU} / \mathrm{mL}$ and higher doses of TC (37.82 or $75.64 \mathrm{mM}$ ) reduced counts below detection within $10 \mathrm{~min}$. The counts were also reduced below detection by all three doses of EG and CR.

At $37^{\circ} \mathrm{C}$ in the broth medium, 33.28 or $66.56 \mathrm{mM} \mathrm{CR}$ or $60.90 \mathrm{mM}$ EG was the most effective and reduced the counts below detection limit in $1 \mathrm{~min}$. In addition, TC at 18.91, 37.82, and $75.64 \mathrm{mM}$ reduced C. jejuni counts by $2.8,3.7$, and $4 \mathrm{Log}$ $\mathrm{CFU} / \mathrm{mL}$, respectively, in $10 \mathrm{~min}$ exposure time. Similar results were observed in the presence of chicken juice where 33.28 or $66.56 \mathrm{mM}$ of CR and $60.90 \mathrm{mM}$ EG were the most effective treatments and reduced C. jejuni counts by $\sim 7.7$ Log CFU/mL. In addition, the antibacterial activities of the TC, EG, and CR were significantly increased with an increase in exposure time on steel coupons $(P<0.05)$. For example, at $37^{\circ} \mathrm{C}$ in the presence of chicken juice, $16.64 \mathrm{mM}$ CR had significantly a higher reduction in $10 \mathrm{~min}$ than in $1 \mathrm{~min}$ exposure time (reductions $\sim 5.5$ vs. $3 \log \mathrm{CFU} / \mathrm{mL}$ ).

\section{Effect of Phytochemicals on Mature Biofilms Architecture and Viability of C. jejuni in the Biofilms}

The effect of TC, EG, and CR on the biofilm architecture and viability of $C$. jejuni in the biofilms was visualized using ESEM and CLSM (Figure 4). The biofilm structure was intact and covered with EPS in control C. jejuni biofilm not exposed to phytochemicals (Figure $\mathbf{4 A}$ ), whereas the exposure to TC (18.91 mM), EG (15.22 mM), and CR (16.64 mM) for $10 \mathrm{~min}$ removed a majority of the biofilm structure as depicted by loss of EPS and scattering of C. jejuni cells (Figures 4B-D, respectively). In addition, confocal microscopy revealed that the majority of C. jejuni were live (stained green) in the control biofilms, and dead (stained red) after treatments with TC, EG, and CR for 10 min (Figures 4a-d).

\section{Effect of Phytochemicals on the Expression of C. jejuni Genes Coding for Biofilm Formation}

Figure 5 shows the effect of TC, EG, and CR on the expression of $C$. jejuni genes critical for biofilm formation. Phytochemicals at SICs level significantly modulated the expression of genes encoding for motility, cell surface modifications, stress response and quorum sensing. The SIC of TC significantly downregulated bacterial cell mobility genes $f l a A, f l a B$, and $f \lg A$ by $\sim 11.7,9$, and 4.3-fold, respectively (Figure 5A). However, quorum sensing gene $(\operatorname{luxS})$ responsible for cell to cell communication during biofilm formation was upregulated by $\sim \operatorname{sixfold}(P<0.05)$. The expression of stress response genes $(\cos R, a h p C)$ was not affected by TC treatment $(P>0.05)$. Similar to TC, CR also downregulated motility genes $f l a A, f l a B, f l g A$ and upregulated luxS (Figure 5B). The phytochemical EG downregulated (fold change $>2$ ) majority of the tested genes (flaA, flaB, flaG, $f \lg A, w a a F, \cos R$, and $a h p C)$ critical for C. jejuni biofilm formation (Figure 5C).

\section{Effect of Phytochemicals on C. jejuni Biofilm Proteome}

Overall, 76 proteins were identified in the proteome of $C$. jejuni present in the biofilms. Table 4 shows the differential protein expression of $C$. jejuni in biofilms subjected to phytochemicals treatment as compared to control biofilms. The presence of SIC of TC significantly upregulated three proteins and downregulated three proteins critical for biofilm formation $(P<0.05)$. The upregulated proteins were flagellar protein (FliL), cytochrome c553 (Cyf) and putative peptidyl-prolyl cisisomerase (Cbf2), whereas periplasmic nitrate reductase (NapA), chaperone (DnaK), and bacterioferritin were downregulated. Similar results were observed with EG, which upregulated cytochrome c553 (Cyf) and downregulated NapA $(P<0.05)$. The SIC of CR significantly upregulated NapB and FliL proteins and downregulated NapA and DnaK proteins. However, other identified proteins were not affected by the presence of phytochemicals $(P>0.05)$.

\section{DISCUSSION}

Campylobacter contamination of poultry products represents a major risk factor for human campylobacteriosis. Despite being nutritionally fastidious, there is sufficient evidence that biofilm formation plays a critical role in the survival of $C$. jejuni in the processing environment (Murphy et al., 2006; García-Sánchez et al., 2017; Castro et al., 2018). The role of C. jejuni biofilm as a source of carcass contamination at the poultry processing facility is currently unknown especially since a comprehensive study determining $C$. jejuni biofilm at processing plant facility is lacking. Therefore, as a first step toward understanding the role of $C$. jejuni biofilms as a source of potential carcass contamination, we have developed C. jejuni biofilms on various surfaces commonly encountered in the processing plant and at conditions mimicking the processing plant environment. Furthermore, the efficacy of phytochemicals in killing C. jejuni biofilms was investigated.

The antibiofilm potential of phytochemicals was tested in the presence of $5 \%$ chicken meat juice to represent the meat environment as it has been shown previously that the presence of meat extracts modulates biofilm formation in C. jejuni (Brown et al., 2014). Brown et al. (2014) had also reported that chicken and pork meat juice (5-100\%) enhanced C. jejuni biofilm formation by increasing attachment of $C$. jejuni to abiotic surfaces.

In order to effectively control C. jejuni biofilms in the processing plant, both prevention of biofilm formation and killing of pre-formed mature biofilms are important. Therefore, we tested the efficacy of phytochemicals in reducing biofilm formation as well as inactivating mature $C$. jejuni biofilms. We used the SIC of phytochemicals in the inhibition studies and hypothesized that the phytochemicals affect the critical genes and proteins required by planktonic cells for biofilm formation. The biofilms were developed for $48 \mathrm{~h}$ since our results (data not shown) and literature (Reeser et al., 2007) suggest that C. jejuni forms mature biofilm by $48 \mathrm{~h}$. Carvacrol was most 


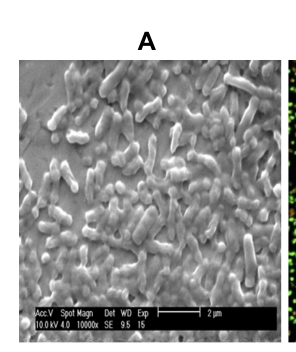

a

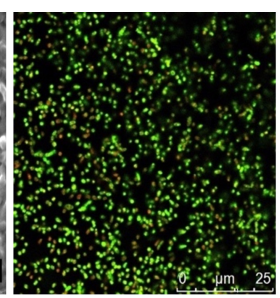

C

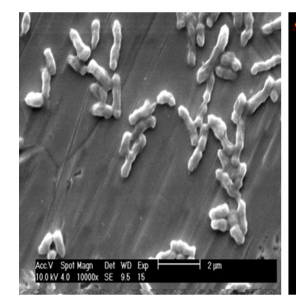

c

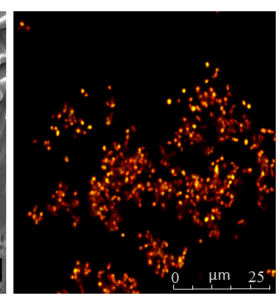

B

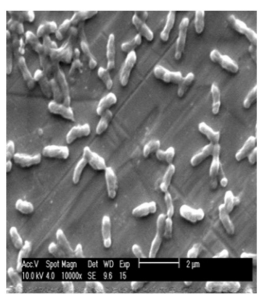

D

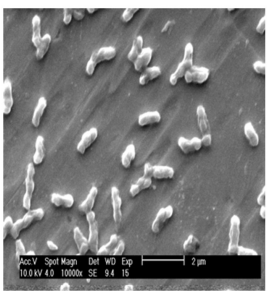

b

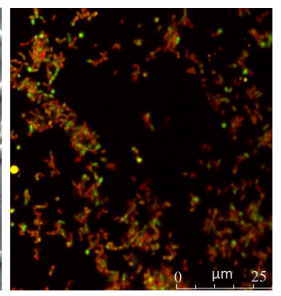

d

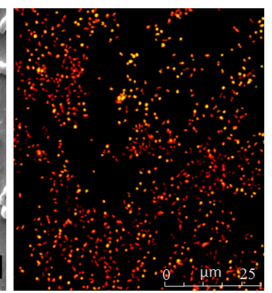

FIGURE 4 | Environmental scanning electron microscopy (ESEM) and confocal laser scanning micrographs (CLSM) of Campylobacter jejuni NCTC 11168 biofilm before treatment with phytochemicals (controls; A,a) and after treatment with $18.91 \mathrm{mM}$ of trans-cinnamaldehyde (B,b), $15.22 \mathrm{mM}$ eugenol (C,c), or 16.64 mM carvacrol (D,d). C. jejuni (6 Log CFU) was inoculated on stainless-steel coupons and Lab-Tek two-chamber (no. 1) borosilicate coverglass system for ESEM and CLSM, respectively, to develop biofilms at $37^{\circ} \mathrm{C}$ for 2 days. The biofilms were exposed to phytochemicals for 10 min followed by gentle washing. For the ESEM (A-D), the treated biofilms were fixed with 2.5\% glutaraldehyde and dehydrated in a series of ethanol concentration (30-100\%). Dried biofilms were coated with gold using Emitech SC7620 sputter coater and visualized using $10 \mathrm{kV}$ beam in ESEM. For the CLSM (a-d), the treated biofilms were stained with 0.01 mM SYTO (green dye) and $0.06 \mathrm{mM}$ propidium iodide (red) for $20 \mathrm{~min}$, and visualized at $63 \times$ objective in Leica SP5 confocal microscope.

effective in inhibiting C. jejuni biofilms formation on polystyrene plates at $24 \mathrm{~h}$ (Figure 2), whereas these phytochemicals were not significantly different in their antibiofilm efficacy among on steel coupons (Figure 3) $(P>0.05)$. Similar results were reported with the SIC of TC, EG, and CR against L. monocytogenes (Upadhyay et al., 2013), where the authors observed significant reductions $(\sim 1.5 \mathrm{Log} \mathrm{CFU} / \mathrm{mL})$ in counts in the biofilms developed for $48 \mathrm{~h}$ at 25 and $37^{\circ} \mathrm{C}$. Although the phytochemicals were effective in reducing $C$. jejuni biofilm formation compared to respective control (Figures 2, 3), they did not inhibit the growth of $C$. jejuni biofilm at $48 \mathrm{~h}$ as compared to $24 \mathrm{~h}$ except at $37^{\circ} \mathrm{C}$ in CEB on steel coupons (Figure $3 \mathbf{B}$ ). This could potentially be due to degradation of phytochemicals leading to reduced efficacy or microbial metabolism of these compounds. However, the exact cause of this observation is not known.

Previous studies have shown that phytochemicals at SICs level significantly modulate the expression of genes critical for virulence of various pathogenic bacteria (Qiu et al., 2010; Maisuria et al., 2016), including C. jejuni (Castillo et al., 2014; Kovács et al., 2016; Upadhyay et al., 2017b; Wagle et al., 2017a,b). However, the potential mechanism of action of TC, EG and CR against C. jejuni genes critical for biofilm formation has not been studied. Therefore, a gene expression study was performed to study the change in gene expression profile of C. jejuni in response to TC, EG and CR. A variety of genes critical for $C$. jejuni biofilm formation has been previously characterized (Bronowski et al., 2014). Bacterial genes encoding flagellins (FlaA, FlaB, and FlaG) and flagellar biosynthesis protein (FlgA) are necessary at the initial stage of $C$. jejuni biofilm formation (Kalmokoff et al., 2006; Kim et al., 2015). Previously, proteomic analysis revealed that flagellins proteins (FlaA, FlaB) were expressed at higher levels in C. jejuni biofilms than in planktonic cells (Kalmokoff et al., 2006). Moreover, C. jejuni flgA mutants were non-motile leading to reduced biofilm formation on food contact surfaces (Kim et al., 2015). Similarly, cellbinding protein (Peb4) and inner core of lipooligosaccharides (WaaF) protect the bacterial cell during stress and contribute to survival by forming biofilm (Asakura et al., 2007; Naito et al., 2010). It was previously reported that CosR is an essential response regulator in $C$. jejuni, which regulates the transcription of oxidative stress genes ( $k a t A, a h p C$ ) (Hwang et al., 2012; Turonova et al., 2015). In addition, CosR is the key protein in the maturation of biofilm and its overexpression was reported to enhance biofilm formation in C. jejuni (Oh and Jeon, 2014). Likewise, quorum sensing or cell-to-cell signaling has been reported to play an important role in the cell attachment to form biofilm. Biofilm formation was significantly reduced in C. jejuni luxS mutants compared to wild-type (Reeser et al., 2007). Therefore, we selected all the aforementioned genes critical for C. jejuni biofilm formation. We observed that TC, EG, and CR at SICs significantly downregulated the expression of select flagellar genes critical for initial attachment during biofilm formation (Figure 5). However, these phytochemicals differ from one another in reducing expression of quorum sensing and stress response genes. For example, EG significantly downregulated $\cos R$ and $a h p C$, however, these genes were not affected by TC and CR. Moreover, quorum sensing gene luxS was upregulated by TC and CR indicating that it could be a bacterial 

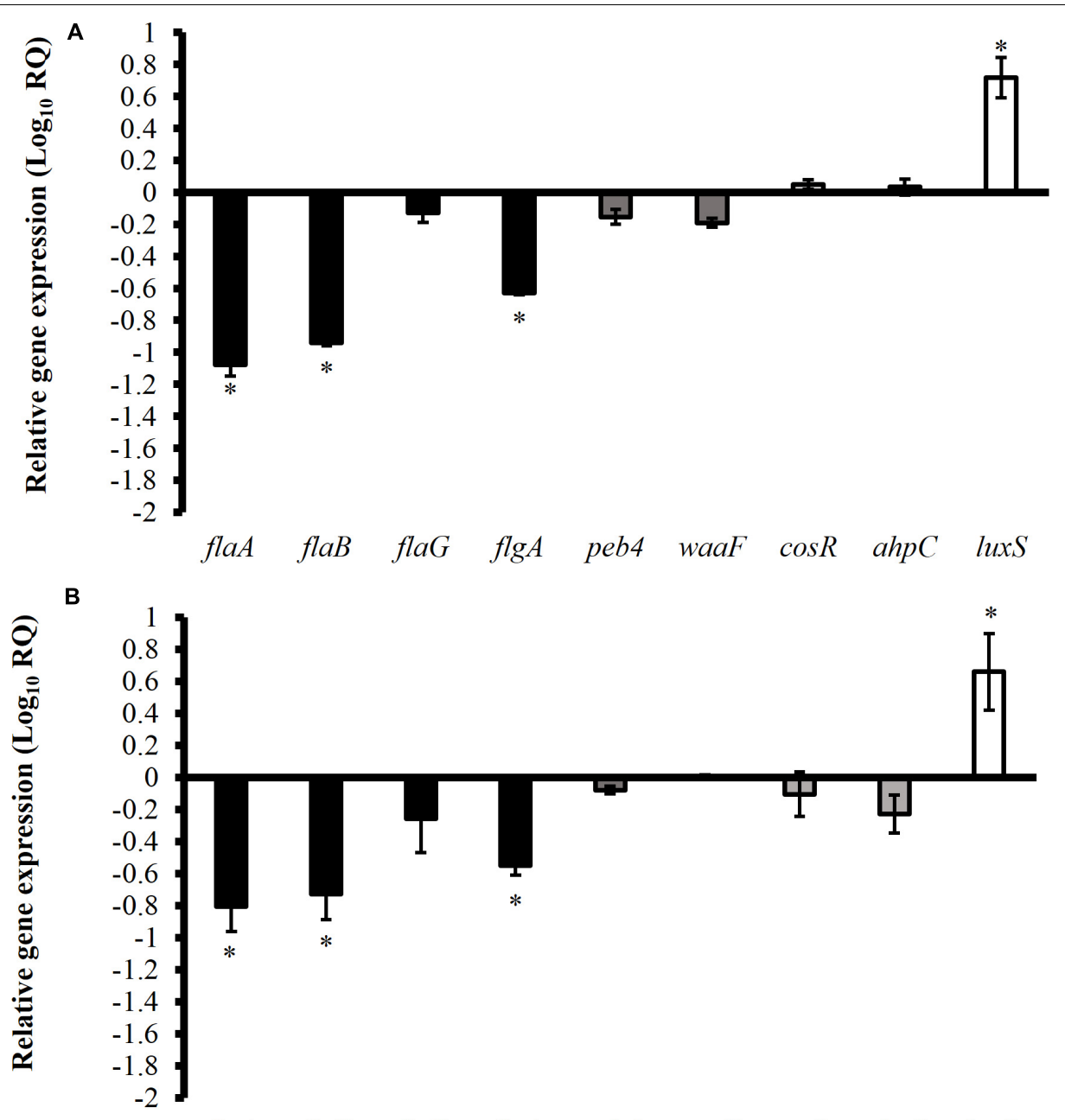

flaA flaB flaG flgA peb4 waaF cosR ahpC luxS

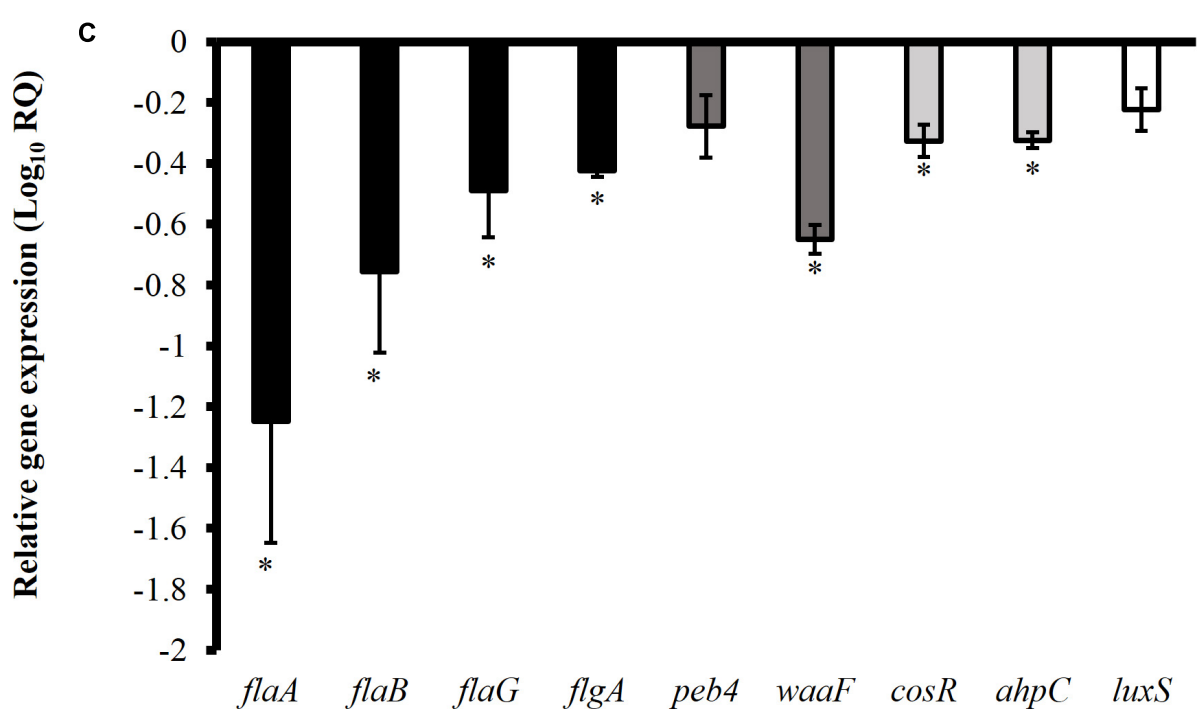

FIGURE 5 | Effect of SICs of trans-cinnamaldehyde (A), carvacrol (B), and eugenol (C) on the expression of Campylobacter jejuni (NCTC 11168) genes critical for biofilm formation. Error bars represent SEM $(n=6)$. C. jejuni ( 6.0 Log CFU/mL) in the presence of TC $(0.75 \mathrm{mM})$, EG $(0.61 \mathrm{mM})$ or CR $(0.13 \mathrm{mM})$ was incubated at $37^{\circ} \mathrm{C}$ for $12 \mathrm{~h}$ followed by RNA extraction and cDNA synthesis. RT-qPCR was conducted with $16 \mathrm{~S}$-rRNA serving as endogenous control. *indicates significant change in the expression of genes at $P<0.05$. 
TABLE 4 | List of identified proteins significantly altered in C. jejuni NCTC 11168 biofilms treated with TC, EG, or CR as compared to untreated (control) biofilms.

\begin{tabular}{|c|c|c|c|}
\hline Proteins name and function(s) & Alternative ID & Molecular weight (kDa) & $P$-value \\
\hline \multicolumn{4}{|l|}{ Upregulated with TC } \\
\hline Putative peptidyl-prolyl cis-trans isomerase & Cbf2 & 30 & 0.039 \\
\hline Cytochrome c553 & Cyf & 11 & 0.002 \\
\hline Flagellar protein FliL & FliL & 20 & 0.047 \\
\hline \multicolumn{4}{|l|}{ Downregulated with TC } \\
\hline Periplasmic nitrate reductase & NapA & 105 & 0.002 \\
\hline Chaperone protein DnaK & Dnak & 67 & 0.016 \\
\hline Bacterioferritin, putative & CJJ81176_1519 & 17 & 0.016 \\
\hline \multicolumn{4}{|l|}{ Upregulated with EG } \\
\hline Cytochrome c553 & Cyf & 11 & 0.025 \\
\hline Uncharacterized protein & CJJ81176_0474 & 8 & 0.035 \\
\hline \multicolumn{4}{|l|}{ Downregulated with EG } \\
\hline Periplasmic nitrate reductase & NapA & 105 & 0.024 \\
\hline Uncharacterized protein & CJJ81176_0974 & 16 & 0.013 \\
\hline \multicolumn{4}{|l|}{ Upregulated with CR } \\
\hline Periplasmic nitrate reductase, electron transfer subunit & NapB & 19 & 0.047 \\
\hline Flagellar protein FliL & FliL & 20 & 0.001 \\
\hline Uncharacterized protein & CJJ81176_1382 & 27 & 0.025 \\
\hline \multicolumn{4}{|l|}{ Downregulated with CR } \\
\hline Periplasmic nitrate reductase & NapA & 105 & 0.016 \\
\hline Chaperone protein DnaK & DnaK & 67 & 0.016 \\
\hline
\end{tabular}

compensatory mechanism against phytochemical treatments. These findings suggest that TC, EG, and CR may act through different mechanism(s).

To determine the effect of TC, EG, and CR on proteome of C. jejuni present in the biofilms, LS-MS/MS based protein identification and quantification of phytochemical-treated and un-treated C. jejuni biofilms was conducted. Periplasmic nitrate reductase (NapABC enzyme) is an enzyme responsible for utilization of nitrate as an energy source for bacterial growth and also protects against oxidative stress (Pittman et al., 2007). Similarly, heat shock protein $70 \mathrm{kD}$ (also known as chaperone DnaK) contributes to motility, stress responses, and pathogenesis in Escherichia coli (Arita-Morioka et al., 2015). A loss of this protein lead to reduction in biofilm formation in Staphylococcus aureus. Similar findings were observed with Streptococcus mutans where it regulates RpoS and CsgD proteins essential for curlidependent biofilm formation (Rockabrand et al., 1998; AritaMorioka et al., 2015). In our proteomic analysis, NapA was significantly downregulated in TC, EG, and CR-treated biofilms as compared to un-treated C. jejuni biofilms (Table 4). The SICs of TC and CR also reduced the expression of DnaK. In addition, we identified a few uncharacterized proteins and the specific roles of such proteins need to be explored in future studies. These results varied from the effect of EG on proteome of C. jejuni planktonic cells where proteins contributing to motility (MotA, MotB, FliA, FliD, FliF, FliL, and FliY) and energy taxis (IlvH, CetA, and CetB) were downregulated (Upadhyaya et al., 2017). In a separate study, TC significantly down-regulated the expression of several proteins (FrdA, AhpC, PstS, CeuE, HemC, and AspA) that contribute to cellular metabolism and stress tolerance on C. jejuni planktonic cells (Upadhyay et al., 2017a). This variation could be due to the differential protein expression between planktonic and biofilm states of C. jejuni as reported by Kalmokoff et al. (2006). In addition, the differential protein/gene expression between two states of C. jejuni could potentially contribute to the discrepancy in results between gene expression and proteomic analysis as the gene expression study was conducted on planktonic cells in the present study. These findings suggest that antibiofilm effect of TC, EG, and CR could potentially be mediated through modulation of these proteins critical for C. jejuni biofilm formation.

To inactivate mature C. jejuni biofilms, we used bactericidal concentrations of phytochemicals and hypothesized that phytochemicals kill biofilm associated C. jejuni by potentially disrupting their cell membrane thereby leading to membrane dysfunction, cellular damage and inactivation of biofilms from the surfaces. C. jejuni biofilms were developed for $48 \mathrm{~h}$ since our TTC staining results suggest that $C$. jejuni biofilm matures by $48 \mathrm{~h}$ (Figure 1). We found that TC, EG and CR were effective in killing C. jejuni in the mature biofilms on polystyrene (Table 2) and steel surface (Table 3 ) at both temperatures. Previously, Lu et al. (2012) had reported inactivation of C. jejuni biofilms after $24 \mathrm{~h}$ treatment time with $1 \mu \mathrm{M}$ concentration of diallyl sulfide (an antimicrobial agent from Allum spp). Antibiofilm efficacy of TC, EG and CR has also been reported against L. monocytogenes (Upadhyay et al., 2013) and E. coli (Perez-Conesa et al., 2006) suggesting that the phytochemicals exert antibiofilm effect on several pathogens, however, commonalities in their mechanism of action against various pathogens or the presence of a single target across pathogens that the plant compounds affect has not been identified yet. Considering these results, the select phytochemicals could be effective in reducing C. jejuni biofilm formation either in monoculture or when present with other biofilm forming foodborne pathogens; however, further 
experiments are needed to validate the results on multispecies biofilm of C. jejuni.

In the inactivation studies, $66.56 \mathrm{mM} \mathrm{CR}$ was the most effective in killing C. jejuni biofilms formed in the presence of chicken meat juice on polystyrene surfaces at both temperatures (Table 2). Similarly, in the presence of chicken meat juice, CR was the most effective followed by EG and TC in inactivating C. jejuni biofilm on stainless-steel coupons at $37^{\circ} \mathrm{C}$ in $1 \mathrm{~min}$ exposure time (Table 3 ). In general, we observed an increase in the antibiofilm effect of TC, EG and CR with an increase in their concentrations and more effective killing was found on biofilm developed at $20^{\circ} \mathrm{C}$ than at $37^{\circ} \mathrm{C}$. The increased effectiveness of phytochemicals at $20^{\circ} \mathrm{C}$ could be due to weak attachment of metabolically active C. jejuni to surfaces at $20^{\circ} \mathrm{C}$ than at $37^{\circ} \mathrm{C}$ after $48 \mathrm{~h}$ as reflected by the absorbance value in TTC staining (Figure 1). Similar results were reported by Reeser et al. (2007) where the absorbance was five times lower at $25^{\circ} \mathrm{C}$ than at $37^{\circ} \mathrm{C}$ in the $\mathrm{C}$. jejuni biofilms developed for $48 \mathrm{~h}$. In our study, phytochemicals were more effective in reducing biofilms developed on steel surfaces (Table 3) than on polystyrene plates (Table 2) owing to good hydrophobicity of plastic surfaces for interaction with bacteria leading to stronger biofilm formation. Previously, Reeser et al. (2007) had determined that the physiochemical properties of the abiotic surfaces affect the C. jejuni attachment on surfaces to form biofilm and reported a higher degree of C. jejuni biofilm on hydrophobic surfaces (polystyrene and polyvinyl chloride) than on hydrophilic surfaces (glass, copper, and steel).

To validate the inactivation results, we visualized the architecture of treated biofilms using ESEM and CLSM. We observed that EPS was detached from bacterial cell surface leading to scattering of $C$. jejuni cells after 10 min of exposure to TC (18.91 mM), EG (15.22 $\mathrm{mM})$, or CR (16.64 mM) (Figures 4A-D). Since EPS is critical for C. jejuni biofilms, loss of EPS could be a potential antibiofilm mechanism of the tested phytochemicals. In addition, predominant C. jejuni in the control were live (green) whereas the majority of C. jejuni were dead (red) after treatments (Figures $4 \mathbf{a}-\mathbf{d}$ ). Similar results of confocal microscopy were reported previously with TC, EG and CR against L. monocytogenes biofilms (Upadhyay et al., 2013).

In conclusion, TC, EG, and CR were effective in reducing C. jejuni biofilm formation and inactivating mature biofilms on polystyrene plates and stainless-steel coupons at 20 and

\section{REFERENCES}

Adams, T. B., Cohen, S. M., Doull, J., Feron, V. J., Goodman, J. I., Marnett, L. J., et al. (2004). The FEMA GRAS assessment of cinnamyl derivatives used as flavor ingredients. Food Chem. Toxicol. 42, 157-185. doi: 10.1016/j.fct.2003.08.021

Adams, T. B., Cohen, S. M., Doull, J., Feron, V. J., Goodman, J. I., Marnett, L. J., et al. (2005). The FEMA GRAS assessment of hydroxy-and alkoxysubstituted benzyl derivatives used as flavor ingredients. Food Chem. Toxicol. 43, 1241-1271. doi: 10.1016/j.fct.2004.12.018

Annan-Prah, A., and Janc, M. (1988). The mode of spread of campylobacter jejuni/coli to broiler flocks. J. Vet. Med. 35, 11-18. doi: 10.1111/j.1439-0450. 1988.tb00461.x

Arita-Morioka, K. I., Yamanaka, K., Mizunoe, Y., Ogura, T., and Sugimoto, S. (2015). Novel strategy for biofilm inhibition by using small molecules targeting $37^{\circ} \mathrm{C}$. This reduction could potentially lead to reduced product contamination in processing plant. However, a correlation between a reduction in C. jejuni biofilm counts and corresponding reductions in pathogen load on carcass has not been conducted and could be a focus of future research. In addition, the effects of phytochemicals in monospecies biofilms of other C. jejuni strains as well as in multispecies C. jejuni biofilms should be evaluated in future studies. Proteomic analysis revealed select genes and proteins critical for biofilm formation were modulated by phytochemicals. However, further experiments are warranted to establish a correlation between changes in gene and corresponding protein expression in the biofilm.

\section{DATA AVAILABILITY}

The raw data supporting the conclusions of this manuscript will be made available by the authors, without undue reservation, to any qualified researcher.

\section{AUTHOR CONTRIBUTIONS}

BW and AU designed the study. BW, IU, SS, KA, RL, and AU conducted the experiments. BW wrote the manuscript. AU, KV, $\mathrm{DD}$, and $\mathrm{AD}$ critically analyzed and revised the manuscript.

\section{FUNDING}

This research was funded in part by the USDA-NIFA-OREI-201751300-26815.

\section{ACKNOWLEDGMENTS}

We have presented this manuscript at the annual meeting of the Poultry Science Association (Wagle et al., 2017c) and at the Plant and Animal Genome Conference XXVII (Wagle et al., 2019). We would like to thank Dr. Betty Martin for valuable microscopic training, and the Arkansas Nano \& Bio Materials Characterization Facility and State Wide Mass Spectrometry Facility of University of Arkansas for use of equipment.

molecular chaperone DnaK. Antimicrob. Agents Chemother. 59, 633-641. doi: 10.1128/AAC.04465-14

Asakura, H., Yamasaki, M., Yamamoto, S., and Igimi, S. (2007). Deletion of peb4 gene impairs cell adhesion and biofilm formation in Campylobacter jejuni. FEMS Microbiol. Lett. 275, 278-285. doi: 10.1111/j.1574-6968.2007.00893.x

Bikandi, J., Millán, R. S., Rementeria, A., and Garaizar, J. (2004). In silico analysis of complete bacterial genomes: PCR, AFLP-PCR and endonuclease restriction. Bioinformatics 20, 798-799. doi: 10.1093/bioinformatics/btg491

Birk, T., Ingmer, H., Andersen, M. T., Jørgensen, K., and Brøndsted, L. (2004). Chicken juice, a food-based model system suitable to study survival of Campylobacter jejuni. Lett. Appl. Microbiol. 38, 66-71. doi: 10.1046/j.1472765x.2003.01446.x

Borges, A., Abreu, A., Dias, C., Saavedra, M., Borges, F., and Simões, M. (2016). New perspectives on the use of phytochemicals as an emergent strategy to 
control bacterial infections including biofilms. Molecules 21:877. doi: 10.3390/ molecules21070877

Boysen, L., Nauta, M., and Rosenquist, H. (2016). Campylobacter spp. and Escherichia coli contamination of broiler carcasses across the slaughter line in danish slaughterhouses. Microb. Risk Anal. 2, 63-67. doi: 10.1016/j.mran.2016. 05.005

Bronnec, V., Turňová, H., Bouju, A., Cruveiller, S., Rodrigues, R., Demnerova, K., et al. (2016). Adhesion, biofilm formation, and genomic features of Campylobacter jejuni Bf, an atypical strain able to grow under aerobic conditions. Front. Microbiol. 7:1002. doi: 10.3389/fmicb.2016.01002

Bronowski, C., James, C. E., and Winstanley, C. (2014). Role of environmental survival in transmission of Campylobacter jejuni. FEMS Microbiol. Lett. 356, 8-19. doi: 10.1111/1574-6968.12488

Brown, H. L., Reuter, M., Hanman, K., Betts, R. P., and van Vliet, A. H. (2015). Prevention of biofilm formation and removal of existing biofilms by extracellular DNases of Campylobacter jejuni. PLoS One 10:e0121680. doi: 10. 1371/journal.pone.0121680

Brown, H. L., Reuter, M., Salt, L. J., Cross, K. L., Betts, R. P., and van Vliet, A. H. (2014). Chicken juice enhances surface attachment and biofilm formation of Campylobacter jejuni. Appl. Environ. Microbiol. 80, 7053-7060. doi: 10.1128/ AEM.02614-14

Burt, S. (2004). Essential oils: their antibacterial properties and potential applications in foods-a review. Int. J. Food Microbiol. 94, 223-253. doi: 10.1016/ j.ijfoodmicro.2004.03.022

Byrd, J. A., Hargis, B. M., Caldwell, D. J., Bailey, R. H., Herron, K. L., McReynolds, J. L., et al. (2001). Effect of lactic acid administration in the drinking water during preslaughter feed withdrawal on Salmonella and Campylobacter contamination of broilers. Poult. Sci. 80, 278-283. doi: 10.1093/ps/80. 3.278

Čabarkapa, I., Čolović, R., Đuragić, O., Popović, S., Kokić, B., Milanov, D., et al. (2019). Anti-biofilm activities of essential oils rich in carvacrol and thymol against Salmonella enteritidis. Biofouling 35, 361-375. doi: 10.1080/08927014. 2019.1610169

Castillo, S., Heredia, N., Arechiga-Carvajal, E., and García, S. (2014). Citrus extracts as inhibitors of quorum sensing, biofilm formation and motility of Campylobacter jejuni. Food Biotechnol. 28, 106-122. doi: 10.1080/08905436. 2014.895947

Castro, A. G., Dorneles, E. M., Santos, E. L., Alves, T. M., Silva, G. R., Figueiredo, T. C., et al. (2018). Viability of Campylobacter spp. in frozen and chilled broiler carcasses according to real-time PCR with propidium monoazide pretreatment. Poult. Sci. 97, 1706-1711. doi: 10.3382/ps/pey020

Cody, A. J., McCarthy, N. D., van Rensburg, M. J., Isinkaye, T., Bentley, S., Parkhill, J., et al. (2013). Real-time genomic epidemiological evaluation of human Campylobacter isolates by use of whole-genome multilocus sequence typing. J. Clin. Microbiol. 51, 2526-2534. doi: 10.1128/JCM.000 66-13

Dhillon, A. S., Shivaprasad, H. L., Schaberg, D., Wier, F., Weber, S., and Bandli, D. (2006). Campylobacter jejuni infection in broiler chickens. Avian. Dis. 50, 55-58. doi: 10.1637/7411-071405r.1

Donlan, R. M. (2002). Biofilms: microbial life on surfaces. Emerg. Infect. Dis. 8, 881-890. doi: 10.3201/eid0809.020063

Donlan, R. M., and Costerton, J. W. (2002). Biofilms: survival mechanisms of clinically relevant microorganisms. Clin. Microbiol. Rev. 15, 167-193. doi: $10.1128 / \mathrm{cmr} \cdot 15.2 .167-193.2002$

Dore, M. H. (2015). "Threats to human health: use of chlorine, an obsolete treatment technology," in Global Drinking Water Management and Conservation, ed. M. H. Dore (Cham: pringer), 197-212. doi: 10.1007/978-3-319-11032-5_9

Fields, J. A., and Thompson, S. A. (2008). Campylobacter jejuni CsrA mediates oxidative stress responses, biofilm formation, and host cell invasion. J. Bacteriol. 190, 3411-3416. doi: 10.1128/JB.01928-07

García-Sánchez, L., Melero, B., Jaime, I., Hänninen, M. L., Rossi, M., and Rovira, J. (2017). Campylobacter jejuni survival in a poultry processing plant environment. Food Microbiol. 65, 185-192. doi: 10.1016/j.fm.2017.02.009

Gradel, K. O., Nielsen, H. L., Schønheyder, H. C., Ejlertsen, T., Kristensen, B., and Nielsen, H. (2009). Increased short-and long-term risk of inflammatory bowel disease after salmonella or Campylobacter gastroenteritis. Gastroenterology 137, 495-501. doi: 10.1053/j.gastro.2009.04.001
Hoffmann, S., Batz, M. B., and Morris, J. G. (2012). Annual cost of illness and quality-adjusted life year losses in the United States due to 14 foodborne pathogens. J. Food Prot. 75, 1292-1302. doi: 10.4315/0362-028X.JFP-11-417

Holley, R. A., and Patel, D. (2005). Improvement in shelf-life and safety of perishable foods by plant essential oils and smoke antimicrobials. Food Microbiol. 22, 273-292. doi: 10.1016/j.fm.2004.08.006

Hwang, S., Zhang, Q., Ryu, S., and Jeon, B. (2012). Transcriptional regulation of the CmeABC multidrug efflux pump and the KatA catalase by CosR in Campylobacter jejuni. J. Bacteriol. 194, 6883-6891. doi: 10.1128/JB.01636-12

Jeong, D. K., and Frank, J. F. (1994). Growth of Listeria monocytogenes at $10^{\circ} \mathrm{C}$ in biofilms with microorganisms isolated from meat and dairy processing environments. J. Food Prot. 57, 576-586. doi: 10.4315/0362-028x-57.7.576

Joshua, G. P., Guthrie-Irons, C., Karlyshev, A. V., and Wren, B. W. (2006). Biofilm formation in Campylobacter jejuni. Microbiology 152, 387-396. doi: 10.1099/ mic. $0.28358-0$

Kalmokoff, M., Lanthier, P., Tremblay, T. L., Foss, M., Lau, P. C., Sanders, G., et al. (2006). Proteomic analysis of Campylobacter jejuni 11168 biofilms reveals a role for the motility complex in biofilm formation. J. Bacteriol. 188, 4312-4320. doi: 10.1128/jb.01975-05

Kim, J. S., Park, C., and Kim, Y. J. (2015). Role of flgA for flagellar biosynthesis and biofilm formation of Campylobacter jejuni NCTC11168. J. Microbiol. Biotechnol. 25, 1871-1879. doi: 10.4014/jmb.1504.04080

Kim, S. H., Park, C., Lee, E. J., Bang, W. S., Kim, Y. J., and Kim, J. S. (2017) Biofilm formation of Campylobacter strains isolated from raw chickens and its reduction with DNase I treatment. Food Control 71, 94-100. doi: 10.4014/jmb. 1703.03052

Knowles, J. R., Roller, S., Murray, D. B., and Naidu, A. S. (2005). Antimicrobial action of carvacrol at different stages of dual-species biofilm development by Staphylococcus aureus and Salmonella enterica serovar typhimurium. Appl. Environ. Microbiol. 71, 797-803. doi: 10.1128/aem.71.2.797-803.2005

Kovács, J. K., Felsö, P., Makszin, L., Pápai, Z., Horváth, G., Ábrahám, H., et al. (2016). Antimicrobial and virulence-modulating effects of clove essential oil on the foodborne pathogen Campylobacter jejuni. Appl. Environ. Microbiol. 82, 6158-6166. doi: 10.1128/aem.01221-16

Lehtola, M. J., Pitkänen, T., Miebach, L., and Miettinen, I. T. (2006). Survival of Campylobacter jejuni in potable water biofilms: a comparative study with different detection methods. Water. Sci. Technol. 54, 57-61. doi: 10.2166/wst. 2006.448

Letsididi, K. S., Lou, Z., Letsididi, R., Mohammed, K., and Maguy, B. L. (2018). Antimicrobial and antibiofilm effects of trans-cinnamic acid nanoemulsion and its potential application on lettuce. LWT 94, 25-32. doi: 10.1016/j.lwt.2018. 04.018

Line, J. E. (2001). Development of a selective differential agar for isolation and enumeration of Campylobacter spp. J. Food Prot. 64, 1711-1715. doi: 10.4315/ 0362-028x-64.11.1711

Lou, Z., Letsididi, K. S., Yu, F., Pei, Z., Wang, H., and Letsididi, R. (2019). Inhibitive effect of eugenol and its nanoemulsion on quorum sensing-mediated virulence factors and biofilm formation by Pseudomonas aeruginosa. J. Food Prot. 82, 379-389. doi: 10.4315/0362-028X.JFP-18-196

Lu, X., Samuelson, D. R., Rasco, B. A., and Konkel, M. E. (2012). Antimicrobial effect of diallyl sulphide on Campylobacter jejuni biofilms. J. Antimicrobial. Chemother. 8, 1915-1926. doi: 10.1093/jac/dks138

Maisuria, V. B., Lopez-de Los Santos, Y., Tufenkji, N., and Déziel, E. (2016). Cranberry-derived proanthocyanidins impair virulence and inhibit quorum sensing of Pseudomonas aeruginosa. Sci. Rep. 6:30169. doi: 10.1038/srep30169

Malik, H., Rajagunalan, S., Kumar, M. S., Kataria, J. L., Anjay, P., Sachan, S., et al. (2017). Assessment of antibiotics effect on planktonic and biofilm forms of Campylobacter Isolates. Israel J. Vet. Med. 72:4.

Marder, E. P., Cieslak, P. R., Cronquist, A. B., Dunn, J., Lathrop, S., Rabatsky-Ehr, T., et al. (2017). Incidence and trends of infections with pathogens transmitted commonly through food and the effect of increasing use of culture-independent diagnostic tests on surveillance-foodborne diseases active surveillance network, 10 US Sites, 2013-2016. MMWR Morb. Mortal. Wkly. Rep. 66, 397-403. doi: 10.15585/mmwr.mm6615al

McLennan, M. K., Ringoir, D. D., Frirdich, E., Svensson, S. L., Wells, D. H., Jarrell, H., et al. (2008). Campylobacter jejuni biofilms up-regulated in the absence of the stringent response utilize a calcofluor white-reactive polysaccharide. J. Bacteriol. 190, 1097-1107. doi: 10.1128/jb.00516-07 
Melo, R. T., Mendonça, E. P., Monteiro, G. P., Siqueira, M. C., Pereira, C. B., Peres, P. A., et al. (2017). Intrinsic and extrinsic aspects on Campylobacter jejuni biofilms. Front. Microbiol. 8:1332. doi: 10.3389/fmicb.2017.01332

Miyamoto, K. N., Monteiro, K. M., da Silva Caumo, K., Lorenzatto, K. R., Ferreira, H. B., and Brandelli, A. (2015). Comparative proteomic analysis of Listeria monocytogenes ATCC 7644 exposed to a sublethal concentration of nisin. J. Proteom. 119, 230-237. doi: 10.1016/j.jprot.2015.02.006

Murphy, C., Carroll, C., and Jordan, K. N. (2006). Environmental survival mechanisms of the foodborne pathogen Campylobacter jejuni. J. Appl. Microbiol. 100, 623-632. doi: 10.1111/j.1365-2672.2006.02903.x

Naito, M., Frirdich, E., Fields, J. A., Pryjma, M., Li, J., Cameron, A., et al. (2010). Effects of sequential Campylobacter jejuni 81-176 lipooligosaccharide core truncations on biofilm formation, stress survival, and pathogenesis. J. Bacteriol. 192, 2182-2192. doi: 10.1128/JB.01222-09

Northcutt, J. K., Smith, D. P., Musgrove, M. T., Ingram, K. D., and Hinton, A. (2005). Microbiological impact of spray washing broiler carcasses using different chlorine concentrations and water temperatures. Poult. Sci. 84, 1648-1652. doi: 10.1093/ps/84.10.1648

Oh, E., and Jeon, B. (2014). Role of alkyl hydroperoxide reductase (AhpC) in the biofilm formation of Campylobacter jejuni. PLoS One 9:e87312. doi: 10.1371/ journal.pone.0087312

Oyarzabal, O. A. (2005). Reduction of Campylobacter spp. by commercial antimicrobials applied during the processing of broiler chickens: a review from the United States perspective. J. Food Prot. 68, 1752-1760. doi: 10.4315/0362028x-68.8.1752

Perez-Conesa, D., McLandsborough, L., and Weiss, J. (2006). Inhibition and inactivation of Listeria monocytogenes and Escherichia coli O157: H7 colony biofilms by micellar-encapsulated eugenol and carvacrol. J. Food Prot. 69, 2947-2954. doi: 10.4315/0362-028x-69.12.2947

Perkins, D. N., Pappin, D. J., Creasy, D. M., and Cottrell, J. S. (1999). Probabilitybased protein identification by searching sequence databases using mass spectrometry data. Electrophoresis 20, 3551-3567. doi: 10.1002/(sici)15222683(19991201)20:18<3551::aid-elps3551>3.0.co;2-2

Pittman, M. S., Elvers, K. T., Lee, L., Jones, M. A., Poole, R. K., Park, S. F., et al. (2007). Growth of Campylobacter jejuni on nitrate and nitrite: electron transport to NapA and NrfA via $\mathrm{NrfH}$ and distinct roles for NrfA and the globin Cgb in protection against nitrosative stress. Mol. Microbiol. 63, 575-590. doi: 10.1111/j.1365-2958.2006.05532.x

Qiu, J., Feng, H., Lu, J., Xiang, H., Wang, D., Dong, J., et al. (2010). Eugenol reduces the expression of virulence-related exoproteins in Staphylococcus aureus. Appl. Environ. Microbiol. 76, 5846-5851. doi: 10.1128/AEM.00704-10

Reeser, R. J., Medler, R. T., Billington, S. J., Jost, B. H., and Joens, L. A. (2007). Characterization of Campylobacter jejuni biofilms under defined growth conditions. Appl. Environ. Microbiol. 73, 1908-1913. doi: 10.1128/aem.007 40-06

Reuter, M., Mallett, A., Pearson, B. M., and van Vliet, A. H. (2010). Biofilm formation by Campylobacter jejuni is increased under aerobic conditions. Appl. Environ. Microbiol. 76, 2122-2128. doi: 10.1128/AEM.01878-09

Rockabrand, D., Livers, K., Austin, T., Kaiser, R., Jensen, D., Burgess, R., et al. (1998). Roles of DnaK and RpoS in starvation-induced thermotolerance of Escherichia coli. J. Bacteriol. 180, 846-854.

Rosner, B. M., Schielke, A., Didelot, X., Kops, F., Breidenbach, J., Willrich, N., et al. (2017). A combined case-control and molecular source attribution study of human Campylobacter infections in Germany, 2011-2014. Sci. Rep. 7:5139.

Siringan, P., Connerton, P. L., Payne, R. J., and Connerton, I. F. (2011). Bacteriophage-mediated dispersal of Campylobacter jejuni biofilms. Appl. Environ. Microbiol. 77, 3320-3326. doi: 10.1128/AEM.02704-10

Somers, E. B., Schoeni, J. L., and Wong, A. C. (1994). Effect of trisodium phosphate on biofilm and planktonic cells of Campylobacter jejuni, Escherichia coli O157: H7, Listeria monocytogenes and Salmonella typhimurium. Int. J. Food Microbiol. 22, 269-276. doi: 10.1016/0168-1605(94)90178-3

Spiller, R. C. (2007). Role of infection in irritable bowel syndrome. J. Gastroenterol. 42, 41-47. doi: 10.1007/s00535-006-1925-8

Svensson, S. L., Davis, L. M., MacKichan, J. K., Allan, B. J., Pajaniappan, M., Thompson, S. A., et al. (2009). The CprS sensor kinase of the zoonotic pathogen Campylobacter jejuni influences biofilm formation and is required for optimal chick colonization. Mol. Microbiol. 71, 253-272. doi: 10.1111/j.1365-2958.2008. 06534.x
Trachoo, N., and Frank, J. F. (2002). Effectiveness of chemical sanitizers against Campylobacter jejuni-containing biofilms. J. Food Prot. 65, 1117-1121. doi: $10.4315 / 0362-028 \mathrm{x}-65.7 .1117$

Trachoo, N., Frank, J. F., and Stern, N. J. (2002). Survival of Campylobacter jejuni in biofilms isolated from chicken houses. J. Food Prot. 65, 1110-1116. doi: 10.4315/0362-028x-65.7.1110

Trevisan, D. A. C., Silva, A. F. D., Negri, M., Abreu Filho, B. A. D., Machinski Junior, M., Patussi, E. V., et al. (2018). Antibacterial and antibiofilm activity of carvacrol against Salmonella enterica serotype typhimurium. Braz. J. Pharm. Sci. 54:e17229.

Turonova, H., Briandet, R., Rodrigues, R., Hernould, M., Hayek, N., Stintzi, A., et al. (2015). Biofilm spatial organization by the emerging pathogen Campylobacter jejuni: comparison between NCTC 11168 and 81-176 strains under microaerobic and oxygen-enriched conditions. Front. Microbiol. 6:709. doi: 10.3389/fmicb.2015.00709

Upadhyay, A., Arsi, K., Wagle, B. R., Shrestha, S., Upadhyaya, I., Bhargava, K., et al. (2017a). In-Water Supplementation of Trans-Cinnamaldehyde Nanoemulsion Reduces Campylobacter jejuni Colonization in Broiler Chickens. Available at: https://www.poultryscience.org/psa17/abstracts/40.pdf (accessed Feburary 28, 2019).

Upadhyay, A., Arsi, K., Wagle, B. R., Upadhyaya, I., Shrestha, S., Donoghue, A. M., et al. (2017b). Trans-cinnamaldehyde, carvacrol, and eugenol reduce Campylobacter jejuni colonization factors and expression of virulence genes in Vitro. Front. Microbiol. 8:713. doi: 10.3389/fmicb.2017.00713

Upadhyay, A., Upadhyaya, I., Kollanoor-Johny, A., and Venkitanarayanan, K. (2013). Antibiofilm effect of plant derived antimicrobials on Listeria monocytogenes. Food Microbiol. 36, 79-89. doi: 10.1016/j.fm.2013.04.010

Upadhyaya, I., Upadhyay, A., Arsi, K., Liyanage, R., Donoghue, A., Rath, N., et al. (2017). Plant-Derived Antimicrobial Eugenol Modulates C. jejuni Proteome and Virulence Critical for Colonization in Chickens. Available at: https://www.poultryscience.org/psa17/abstracts/193.pdf (accessed Feburary 28, 2019).

Wagle, B. R., Arsi, K., Upadhyay, A., Shrestha, S., Venkitanarayanan, K., Donoghue, A. M., et al. (2017a). $\beta$-resorcylic Acid, a phytophenolic compound, reduces Campylobacter jejuni in postharvest poultry. J. Food Prot. 80, 12431251. doi: 10.4315/0362-028X.JFP-16-475

Wagle, B. R., Upadhyay, A., Arsi, K., Shrestha, S., Venkitanarayanan, K., Donoghue, A. M., et al. (2017b). Application of $\beta$-Resorcylic acid as potential antimicrobial feed additive to reduce Campylobacter colonization in broiler chickens. Front. Microbiol. 8:599. doi: 10.3389/fmicb.2017.00599

Wagle, B. R., Upadhyay, A., Arsi, K., Upadhyaya, I., Shrestha, S., Venkitanarayanan, K., et al. (2017c). Phytochemicals Reduce Biofilm Formation and Inactivates Mature Biofilm of Campylobacter jejuni. Available at: https://www.poultryscience.org/psa17/abstracts/21.pdf (accessed Feburary 28, 2019).

Wagle, B. R., Upadhyay, A., Upadhyaya, I., Arsi, K., Shrestha, S., Liyanage, R., et al. (2019). "Plant-derived antimicrobials modulate Campylobacter jejuni proteome essential for biofilm formation," in Proceedings of the Plant \& Animal Genome conference XXVII, San Diego, CA.

Whitchurch, C. B., Tolker-Nielsen, T., Ragas, P. C., and Mattick, J. S. (2002). Extracellular DNA required for bacterial biofilm formation. Science 295, 14871487. doi: $10.1126 /$ science.295.5559.1487

Disclaimer: Mention of a trade name, proprietary product, or specific equipment does not constitute a guarantee or warranty by the USDA and does not imply its approval to the exclusion of other products that may be suitable.

Conflict of Interest Statement: The authors declare that the research was conducted in the absence of any commercial or financial relationships that could be construed as a potential conflict of interest.

Copyright (c) 2019 Wagle, Upadhyay, Upadhyaya, Shrestha, Arsi, Liyanage, Venkitanarayanan, Donoghue and Donoghue. This is an open-access article distributed under the terms of the Creative Commons Attribution License (CC BY). The use, distribution or reproduction in other forums is permitted, provided the original author(s) and the copyright owner(s) are credited and that the original publication in this journal is cited, in accordance with accepted academic practice. No use, distribution or reproduction is permitted which does not comply with these terms. 